\title{
Encapsulating lodine and Copper into Copper(I) Clusters Stabilized by Dichalcogenolate Ligands: Stability, Structure and Optical Properties
}

Camille Latouche, ${ }^{* 1}$ Jian-Hong Liao, ${ }^{2}$ Yi-Juan Li, ${ }^{2}$ Ruei-Yi Shiu, ${ }^{2}$ Vincenzo Barone, ${ }^{3}$ Samia Kahlal, ${ }^{4}$ C. W. Liu ${ }^{2 *}$ and Jean-Yves Saillard ${ }^{4 *}$

${ }^{1}$ Institut des Matériaux Jean Rouxel (IMN), Université de Nantes, CNRS, 2 rue de la Houssinière, BP 32229, 44322 Nantes cedex 3, France

${ }^{2}$ Department of Chemistry, National Dong Hwa University, No. 1, Sec. 2, Da Hsueh Rd. Shoufeng, Hualien 97401 (Taiwan, Republic of China)

${ }^{3}$ Scuola Normale Superiore, Piazza dei Cavalieri 7, 56126, Pisa, Italy

${ }^{4}$ Institut des Sciences Chimiques de Rennes, UMR CNRS 6226, Campus de Beaulieu, 263

av. Général Leclerc, 35042 Rennes, France

\begin{abstract}
The stability of large ligated copper(I) clusters of undeca- and dodeca-nuclearity encapsulating iodide and stabilized by dithio- and diseleno-phosph(in)ates has been investigated by DFT calculations. A bonding analysis is provided which shows strong iono-covalent bonding between the iodide and its host. The electronic structures of the title compounds suggest the possibility for interesting photoluminescent properties, which have been fully investigated by TD-DFT calculations including vibronic contributions to simulate the phosphorescence spectra. The quantum mechanical results have been compared to the experimental data obtained for the new clusters $\left[\mathrm{Cu}_{11}\left(\mu_{9}\right.\right.$ I) $\left.\left(\mu_{3}-\mathrm{I}\right)_{3}\left\{\mathrm{Se}_{2} \mathrm{P}\left(\mathrm{O}^{i} \mathrm{Pr}\right)_{2}\right\}_{6}\right]^{+}$, and $\left[\mathrm{Cu}_{11}\left(\mu_{9}-\mathrm{I}\right)\left(\mu_{3}-\mathrm{I}\right)_{3}\left(\mathrm{Se}_{2} \mathrm{PPh}_{2}\right)_{6}\right]^{+}$, whose synthesis, X-ray structure and full characterization are reported in this paper. From this combined theoretical/experimental investigation, it is suggested that the encapsulation by the same copper(I) cages of a formally $\mathrm{Cu}^{-}$anion is also possible. DFT calculations on these species are consistent with the existence of stable 2-electron superatoms.
\end{abstract}




\section{Introduction}

In the past decades, stable atom-precise molecular clusters composed of Group 11 metals have become a very prolific research field, due to the peculiar properties and potential applications of these compounds in several fields including catalysis, health sciences, electro-optical devices, nanodots, hydrogen storage. ${ }^{1-8}$ In the specific case of clusters in which all the metal atoms are in their $+\mathrm{I}$ oxidation state, only weak metallophilic $\left(\mathrm{d}^{10 \ldots} \mathrm{d}^{10}\right)$ interactions are possible, and therefore the stability and shape of the cluster is largely controlled by the presence of bridging ligands, such as chalcogenolates and halides, which allow maintaining the metallic core in a suitable spatial configuration. In such species, the M(I) atoms are usually bi- or tri-coordinated to the outer ligands. This leaves them with some electronic unsaturation, which, combined with the size of the cluster cavity, favors the encapsulation of anions such as halides, chalcogenides, hydrides, ${ }^{7,9-21}$ or even molecular anions. ${ }^{22,23}$ It is likely that anion encapsulation is essential for stabilizing the structure since the parent empty cluster has not yet been characterized experimentally. In the case of the smaller hydrides, multiple encapsulation is not uncommon and associated with outer capping coordination, leading to giant polyhydrido species.8,24 In the case of the larger main-group elements, encapsulation of a single anion at the center of the cluster cage is generally observed. With the heaviest of them, the cage size (i.e. the metal nuclearity) needs to be sufficiently large to accommodate them. This means reaching an important degree of hypercoordination for the encapsulated element. Such conditions are not so easy to satisfy. For example, entrapping iodide remains highly challenging. Some years ago, we reported the undecanuclear silver cluster $\left[\operatorname{Ag}_{11}\left(\mu_{9}-\mathrm{I}\right)\left(\mu_{3}-\mathrm{I}\right)_{3}\left\{\mathrm{E}_{2} \mathrm{P}\left(\mathrm{O}^{\mathrm{i} P r}\right)_{2}\right\}_{6}\right]^{+}(\mathrm{E}=\mathrm{S}, \mathrm{Se}),{ }^{25}$ in which an encapsulated iodide occupies the center of a silver tricapped trigonal-prism and is bonded to nine metal atoms. ${ }^{25}$ More recently, we reported the dodecanuclear species $\left[\mathrm{Ag}_{12}\left(\mu_{12}-\mathrm{I}\right)\left(\mu_{3}-\mathrm{I}\right)_{4}\left\{\mathrm{~S}_{2} \mathrm{P}\left(\mathrm{CH}_{2} \mathrm{CH}_{2} \mathrm{Ph}\right)_{2}\right\}_{6}\right]^{+}$in which the twelve-coordinated iodide lies at the center of a silver cuboctahedron. ${ }^{26} \mathrm{~A}$ similar cluster core framework was also reported in the copper species $\left[\left\{\mathrm{TpMo}\left(\mu_{3}-\mathrm{S}\right)_{4} \mathrm{Cu}_{3}\right\}_{4}\left(\mu_{12}-\mathrm{I}\right)\right]^{+}(\mathrm{Tp}=$ hydridotris(pyrazol-1yl)borate). ${ }^{27}$ In this combined experimental-theoretical paper, we focus on the encapsulation of iodide in undeca- and dodeca-nuclear $\mathrm{Cu}$-based clusters. The synthesis, characterization and structure of two new clusters, namely $\left[\mathrm{Cu}_{11}\left(\mu_{9}-\mathrm{I}\right)\left(\mu_{3}-\right.\right.$ 
I) $\left.{ }_{3}\left\{\mathrm{Se}_{2} \mathrm{P}\left(\mathrm{O}^{i} \mathrm{Pr}\right)_{2}\right\}_{6}\right](\mathrm{OH})$ (1-Se-a), and $\left[\mathrm{Cu}_{11}\left(\mu_{9}-\mathrm{I}\right)\left(\mu_{3}-\mathrm{I}\right)_{3}\left(\mathrm{Se}_{2} \mathrm{PPh}_{2}\right)_{6}\right]\left(\mathrm{PF}_{6}\right)$ (1-Se-b), are described. The bonding in these and other hypothetical compounds is analyzed on the grounds of Density Functional Theory (DFT) calculations. Time-Dependent DFT (TDDFT) calculations permit a comprehensive analysis of optical properties (including phosphorescence, for which vibronic interactions have been included for a more realistic simulation of the spectra). Finally, the possibility for substituting the encapsulated halide in both penta-capped trigonal prismatic and cuboctahedral cages by a formally $\mathrm{Cu}^{-}$metal anion, leading to the stabilization of 2-electron superatoms, is proposed.

\section{Computational Details}

DFT calculations were carried out using a locally modified version of the Gaussian 09 package $^{28}$, employing the global hybrid PBE0 functional, ${ }^{29,30}$ and using the general triple- $\xi$ polarized basis set, namely the Def2-TZVP set. ${ }^{31}$ These functional and basis set were chosen as the result of systematic investigations of $\mathrm{Cu}(\mathrm{I})$ and $\mathrm{Ag}(\mathrm{I})$ clusters, ${ }^{12,13,32-}$ 35 and provide a good ratio between accuracy and computational efforts for both electronic structures and optical properties with transition metal atoms. ${ }^{36}$ Based on previous investigations, ${ }^{12,25,35}$ the substituents $\mathrm{OR}$ and $\mathrm{R}$ on the ligands have been replaced by hydrogen atoms. All stationary points were fully characterized as true minima via analytical frequency calculations. Geometries obtained from DFT calculations were used to perform natural orbital analysis with the NBO 5.0 program ${ }^{37}$ as well as TD-DFT calculations.

The rather complex architectures of the studied clusters suggest that the singlet (ground state) and triplet (excited state) states could show non-negligible geometrical variations. This observation prompted us to further refine our usual computational protocol to include vibronic contributions. ${ }^{38-44}$ Therefore we employed the so-called Adiabatic Hessian $(\mathrm{AH})$ model, which requires harmonic frequencies of the initial and final electronic state at their respective equilibrium structures. This is the most refined computational model at the harmonic level and takes into full account mode-mixing and local shapes of adiabatic potential energy surfaces. A small number of normal modes with very low frequencies have been neglected in the vibronic treatment due to the intrinsic limits of the harmonic approximation and the negligible effect of these modes on spectral shapes at least in the region sampled by experiments. Simulated electronic 
absorption spectra as well as transitions were obtained using the VMS package. ${ }^{45}$ The composition of the Kohn-Sham orbitals was analyzed using the AOmix program. ${ }^{46}$ Calculations of the simulated volume have been performed using the VESTA program. ${ }^{47,48}$

\section{Experimental}

\section{Reagents and general procedures}

All chemicals were purchased from commercial sources and used as received. Solvents were purified following standard protocols. All reactions were performed in oven-dried Schlenk glassware using standard inert atmosphere techniques and were carried out under $\mathrm{N}_{2}$ atmosphere by using standard Schlenk techniques. $\left[\mathrm{Cu}\left(\mathrm{CH}_{3} \mathrm{CN}\right)_{4}\right]\left(\mathrm{PF}_{6}\right)$ and $\mathrm{NH}_{4}\left(\mathrm{Se}_{2} \mathrm{PR}_{2}\right)\left(\mathrm{R}=\mathrm{O}^{\mathrm{P}} \mathrm{Pr}, \mathrm{Ph}\right)$ were prepared by a slightly modified procedure reported earlier in literature. NMR spectra were recorded on a Bruker Advance DPX300 FT-NMR spectrometer. The chemical shift $(\delta)$ and coupling constant (J) are reported in ppm and $\mathrm{Hz}$, respectively. ${ }^{31} \mathrm{P}$ NMR spectra were referenced to external $85 \% \mathrm{H}_{3} \mathrm{PO}_{4}$ at $\delta$ 0.00. ESI-mass spectra were recorded on a Fison Quattro Bio-Q (Fisons Instruments, VG Biotech, U. K.). UV-Visible absorption spectra were measured on a Perkin Elmer Lambda 750 spectrophotometer using quartz cells with path length of 1 cm. Emission spectra were recorded using a Cary Eclipse B10 fluorescence spectrophotometer.

\section{Synthesis of Compounds}

$\left[\mathrm{Cu}_{11}\left(\mu_{9}-\mathrm{I}\right)\left(\mu_{3}-\mathrm{I}\right)_{3}\left\{\mathrm{Se}_{2} \mathrm{P}\left(\mathrm{O}^{i} \mathrm{Pr}\right)_{2}\right\}_{6}\right](\mathrm{OH})$, 1-Se-a: $\left[\mathrm{Cu}\left(\mathrm{CH}_{3} \mathrm{CN}\right)_{4}\right]\left(\mathrm{PF}_{6}\right)(0.21$ g, 0.56 mmol) and $\mathrm{NH}_{4}\left[\mathrm{Se}_{2} \mathrm{P}\left(\mathrm{O}^{i} \mathrm{Pr}\right)_{2}\right](0.10 \mathrm{~g}, 0.31 \mathrm{mmol})$ in $20 \mathrm{~mL}$ methanol at $-20{ }^{\circ} \mathrm{C}$ were stirred for one hour under a nitrogen atmosphere. Then $\mathrm{Bu}_{4} \mathrm{NI}(0.075 \mathrm{~g}, 0.20 \mathrm{mmol})$ was added, yellow precipitate formed and the mixture solution was continuing stirred for 60 min. The yellow precipitate was collected by filtration and washed with methanol to obtain the yellow powder, $\left[\mathrm{Cu}_{11}\left(\mu_{9}-\mathrm{I}\right)\left(\mu_{3}-\mathrm{I}\right)_{3}\left\{\mathrm{Se}_{2} \mathrm{P}\left(\mathrm{O}^{i} \mathrm{Pr}\right)_{2}\right\}_{6}\right](\mathrm{OH})$ 1-Se-a. Yield: $0.13 \mathrm{~g}$ (81\%). ${ }^{1} \mathrm{H}$ NMR(300 MHz, $\mathrm{CDCl}_{3}$ ): $\delta 1.44$ [d, 36H, CH 3$], \delta 1.47$ [d, 36H, $\left.\mathrm{CH}_{3}\right], \delta 4.93[\mathrm{~m}, 6 \mathrm{H}$, $\mathrm{CH}], \delta 5.13[\mathrm{~m}, 6 \mathrm{H}, \mathrm{CH}] .{ }^{31} \mathrm{P}\left\{{ }^{1} \mathrm{H}\right\} \mathrm{NMR}\left(121 \mathrm{MHz}, \mathrm{CDCl}_{3}\right): \delta 74.3[\mathrm{~s}, 6 \mathrm{P}, \mathrm{JPSe}=664.8 \mathrm{~Hz}$, $\mathrm{JPSe}=661.7 \mathrm{~Hz}$ ]. ${ }^{77} \mathrm{Se}\left\{{ }^{1} \mathrm{H}\right\} \mathrm{NMR}\left(57 \mathrm{MHz}, \mathrm{CDCl}_{3}\right): \delta 38.8$ (d, JSeP=642 Hz, 6Se), $\delta 30.0$ (dd, $\mathrm{J}_{\mathrm{SeP}}=654 \mathrm{~Hz}, 6 \mathrm{Se}$ ). Anal. Calcd for $\mathrm{C}_{36} \mathrm{H}_{85} \mathrm{Cu}_{11} \mathrm{I}_{4} \mathrm{O}_{13} \mathrm{P}_{6} \mathrm{Se}_{12}$ : C, 14.10; H, 2.79. Found: C, 14.15; 
H, 3.19. UV-Vis $\left(\mathrm{CH}_{2} \mathrm{Cl}_{2}\right): \lambda_{\max }(\varepsilon$ м) 402 (10000). ESI-MS: $m / z$ (calcd) 3048.6 (3049.3) $[\mathrm{M}]^{+}$, m.p. : $168^{\circ}$ C. I.R. : $v(\mathrm{OH}): 3427 \mathrm{~cm}^{-1}$.

$\left[\mathrm{Cu}_{11}\left(\mu_{9}-\mathrm{I}\right)\left(\mu_{3}-\mathrm{I}\right)_{3}\left\{\mathrm{Se}_{2} \mathrm{P}\left(\mathrm{C}_{6} \mathrm{H}_{5}\right)_{2}\right\}_{6}\right]\left(\mathrm{PF}_{6}\right)$ 1-Se-b: It was synthesized in a similar way by using $\mathrm{NH}_{4}\left[\mathrm{Se}_{2} \mathrm{P}\left(\mathrm{C}_{6} \mathrm{H}_{5}\right)_{2}\right]$ in THF. Yield: 0.093g (63.10\%), ${ }^{1} \mathrm{H}$ NMR $\left(300 \mathrm{MHz}, \mathrm{CDCl}_{3}, \delta\right.$, ppm): $\delta=7.29-7.95(\mathrm{~m}, 60 \mathrm{H}, \mathrm{Ph}) \mathrm{ppm} .{ }^{31} \mathrm{P}\left\{{ }^{1} \mathrm{H}\right\}$ NMR $\left(121.49 \mathrm{MHz}, \mathrm{CH}_{2} \mathrm{Cl}_{2}, \delta, \mathrm{ppm}\right): 32.4$

$\left.U_{\mathrm{P}-\mathrm{Se}}=530.9 \mathrm{~Hz}, 530.7\right),-143.0$ (septet, $J_{\mathrm{P}-\mathrm{F}}=708 \mathrm{~Hz}$ ); Anal. Calcd for $\mathrm{C}_{72} \mathrm{H}_{60} \mathrm{Cu}_{11} \mathrm{~F}_{6} \mathrm{I}_{4} \mathrm{P}_{7} \mathrm{Se}_{12} \cdot 2 \mathrm{CH}_{2} \mathrm{Cl}_{2}:$ C, 24.83; H, 1.80\%. Found: C, 24.44; H, 1.64\%. UV-Vis $\left(\mathrm{CH}_{2} \mathrm{Cl}_{2}\right): \lambda_{\max }\left(\varepsilon_{\mathrm{M}}\right) 440$ (12000). ESI-MS m/z (calcd): $3265.3(3264.1)[\mathrm{M}]^{+}, \mathrm{mp:} 150^{\circ} \mathrm{C}$.

\section{X-ray Crystallography}

Crystallographic data of $\left[\mathrm{Cu}_{11}\left(\mu_{9}-\mathrm{I}\right)\left(\mu_{3}-\mathrm{I}\right)_{3}\left\{\mathrm{Se}_{2} \mathrm{P}\left(\mathrm{O}^{i} \mathrm{Pr}\right)_{2}\right\}_{6}\right]^{+}(\mathbf{1 - S e}-\mathbf{a})$, and $\left[\mathrm{Cu}_{11}\left(\mu_{9}-\right.\right.$ I) $\left.\left(\mu_{3}-\mathrm{I}\right)_{3}\left(\mathrm{Se}_{2} \mathrm{PPh}_{2}\right)_{6}\right]\left(\mathrm{PF}_{6}\right)$ (1-Se-b), which has solvated dichloromethane and tetrahydrofuran molecules, are given in Table 1. Yellow crystals of 1-Se-a were obtained by slow diffusion of hexane into acetone solution. Orange crystals of 1-Se-b were obtained from a layer of hexane into dichloromethane solution in the same glass tube. Intensity data of both compounds were collected at 296(2) K on a Bruker APEX-II CCD diffractometer $\left(\right.$ Mo $\mathrm{K}_{\alpha}, \lambda=0.71073 \AA$ ) .

The data were processed by using the SAINT software for data reduction. ${ }^{49}$ The absorption corrections for area detector were performed with SADABS program. ${ }^{50}$ Structures were solved by direct methods and refined by least-squares against $F^{2}$ using the SHELXL-2014/7 software package incorporated in SHELXTL/PC V6.14. ${ }^{51}$ All nonhydrogen atoms were refined anisotropically. In the structure of 1-Se-a, two isopropoxy groups, 07 and 08, were refined as a disorder over two positions, each in $50 \%$ occupancy. However, searching counter anion from the Fourier difference maps was unsuccessful. The residual electron densities can be modeled as neither a $\mathrm{PF}_{6}{ }^{-}$nor an iodide anion. As a result, a hydroxide is proposed as a counter anion, which could not be located precisely from the final Fourier difference map due to a severely disordered issue but confirmed by the Infrared spectroscopy. In structure 1-Se-b, $\mathrm{CH}_{2} \mathrm{Cl}_{2}$ and THF solvent molecules were found. THF was disordered at two positions of which the crystallographic mirror plane passes through its center. The structures (1-Se-a and 1Se-b) reported herein have been deposited at the Cambridge Crystallographic Data Center, CCDC-1546828 (1-Se-a) and 1546829 (1-Se-b) contain the supplementary 
crystallographic data for this paper. These data can be obtained free of charge from at the Cambridge Crystallographic Data Centre via www.ccdc.cam.ac.uk/data_request/cif.

Table 1. Selected crystallographic data of compounds 1-Se-a and 1-Se-b.

\begin{tabular}{|c|c|c|}
\hline & 1-Se-a & $\begin{array}{c}\text { 1-Se-b } \\
\cdot 0.5\left(\mathrm{CH}_{2} \mathrm{Cl}_{2}\right) \cdot\left(\mathrm{C}_{4} \mathrm{H}_{8} \mathrm{O}\right)\end{array}$ \\
\hline Formula & $\mathrm{C}_{36} \mathrm{H}_{84} \mathrm{Cu}_{11} \mathrm{I}_{4} \mathrm{O}_{12} \mathrm{P}_{6} \mathrm{Se}_{12}$ & $\mathrm{C}_{76.5} \mathrm{H}_{69} \mathrm{ClCu}_{11} \mathrm{~F}_{6} \mathrm{I}_{4} \mathrm{P}_{7} \mathrm{Se}_{12}$ \\
\hline FW & 3048.91 & 3524.61 \\
\hline Space group & $P 2_{1} / n$ & Pnma \\
\hline a, $\AA$ & $14.4102(13)$ & $22.5155(8)$ \\
\hline $\mathrm{b}, \AA$ & $23.152(2)$ & $18.1031(6)$ \\
\hline c, $\AA$ & $24.441(2)$ & $26.3814(9)$ \\
\hline$\alpha, \operatorname{deg}$ & 90 & 90 \\
\hline$\beta$, deg & $91.922(2)$ & 90 \\
\hline$\gamma$, deg & 90 & 90 \\
\hline $\mathrm{V}, \AA^{3}$ & $8149.4(13)$ & $10753.1(6)$ \\
\hline $\mathrm{Z}$ & 4 & 4 \\
\hline$\rho_{\text {calcd, }} \mathrm{Mg} \mathrm{m}^{-3}$ & 2.485 & 2.177 \\
\hline$\mu, \mathrm{mm}^{-1}$ & 9.843 & 7.515 \\
\hline $\mathrm{T}, \mathrm{K}$ & $296(2)$ & $296(2)$ \\
\hline measured reflections & 83115 & 93688 \\
\hline independent reflections & $14340\left[\mathrm{R}_{\mathrm{int}}=0.0601\right]$ & $9795\left[\mathrm{R}_{\mathrm{int}}=0.0444\right]$ \\
\hline$\theta_{\text {max }}$ deg. / Completeness, $\%$ & $25.0 / 100.0$ & $25.0 / 100.0$ \\
\hline restraints / parameters & 1123 / 825 & $656 / 445$ \\
\hline$R 1^{a}, w R 2^{b}[\mathrm{I}>2 \sigma(\mathrm{I})]$ & $0.0572,0.1604$ & $0.0591,0.1593$ \\
\hline$R 1^{a}, w R 2^{b}$ (all data) & $0.0817,0.1815$ & $0.0772,0.1775$ \\
\hline goodness of fit & 1.033 & 1.083 \\
\hline largest diff peak and hole, e/ $\AA^{3}$ & 1.592 and -2.442 & 2.188 and -1.581 \\
\hline
\end{tabular}

\section{Results and discussions}

\section{Structural analysis of the computed undeca-and dodeca-nuclear models}

The geometries of the undecanuclear models $\left[\mathrm{Cu}_{11}\left(\mu_{9}-\mathrm{I}\right)\left(\mu_{3}-\mathrm{I}\right)_{3}\left\{\mathrm{E}_{2} \mathrm{P}(\mathrm{OH})_{2}\right\}_{6}\right]^{+}(\mathrm{E}=$ S, Se), hereafter labelled 1-S and 1-Se, were first optimized enforcing ideal $C_{3 h}$ symmetry. The principal structural parameters (Table 2) are consistent with those reported in the X-ray structures of $\left[\mathrm{Ag}_{11}\left(\mu_{9}-\mathrm{Se}\right)\left(\mu_{3}-\mathrm{Br}\right)_{3}\left\{\mathrm{Se}_{2} \mathrm{P}(\mathrm{OR})_{2}\right\}_{6}\right]\left(\mathrm{R}=\mathrm{Et}\right.$, ${ }^{\mathrm{i}} \mathrm{Pr}$, and $\left.{ }^{2} \mathrm{Bu}\right],{ }^{52,53}\left[\mathrm{Ag}_{11}\left(\mu_{9}-\mathrm{I}\right)\left(\mu_{3}-\mathrm{I}\right)_{3}\left\{\mathrm{E}_{2} \mathrm{P}\left(\mathrm{O}^{\mathrm{P} P r}\right)_{2}\right\}_{6}\right]\left(\mathrm{PF}_{6}\right) \quad[\mathrm{E}=\mathrm{S}, \quad \mathrm{Se}]^{25}$ and $\left[\mathrm{Cu}_{11}\left(\mu_{9}-\mathrm{Se}\right)\left(\mu_{3^{-}}\right.\right.$ $\left.\mathrm{Br})_{3}\left\{\mathrm{Se}_{2} \mathrm{P}(\mathrm{OR})_{2}\right\}_{6}\right]\left(\mathrm{R}=\mathrm{Et}, \mathrm{Pr},{ }^{\mathrm{i}} \mathrm{Pr}\right)$ clusters. $^{54}$ The eleven copper atoms occupy the vertices of a pentacapped trigonal prism with an iodide at the center of the polyhedron (Figure 1, left). The six $\mathrm{Cu}_{\mathrm{a}}$ atoms correspond to the trigonal prism vertices, the three 
rectangular faces of which are capped by $\mathrm{Cu}_{\mathrm{b}}$ metals and the two triangular faces by two $\mathrm{Cu}_{c}$ centers (Figure 1, right). The $\mathrm{Cu}_{11}\left(\mu_{9}-\mathrm{I}\right)$ core has ideal $D_{3 h}$ symmetry, whereas the whole $\left[\mathrm{Cu}_{11}\left(\mu_{9}-\mathrm{I}\right)\left(\mu_{3}-\mathrm{I}\right)_{3}\left\{\mathrm{E}_{2} \mathrm{P}(\mathrm{OH})_{2}\right\}_{6}\right]^{+}\left(\mathrm{E}=\mathrm{S}\right.$, Se) clusters are of ideal $C_{3 h}$ symmetry. All the dichalcogenophosphate ligands are tetra-connected $\left(\mu_{2}, \mu_{2}\right)$. The encapsulated $\mu_{9}$ iodide is involved in three shorter $\left(\mathrm{Cu}_{\mathrm{b}}-\mathrm{I}\right)$ and six larger $\left(\mathrm{Cu}_{\mathrm{a}}-\mathrm{I}\right)$ bonds $(2.855 \AA$ and $3.136 \AA$, respectively in the $\mathrm{E}=\mathrm{S}$ model). On the other hand, the $\mathrm{Cu}_{\mathrm{c}}-\mathrm{I}$ distances are large (3.669 $\AA$ in the $\mathrm{E}=\mathrm{S}$ model), precluding the existence of bonds.

Table 2. Relevant metrical parameters computed for the $\left[\mathrm{Cu}_{11}\left(\mu_{9}-\mathrm{I}\right)\left(\mu_{3}-\mathrm{I}\right)_{3}\left\{\mathrm{E}_{2} \mathrm{P}(\mathrm{OH})_{2}\right\}_{6}\right]^{+}$and $\left[\mathrm{Cu}_{12}\left(\mu_{12}-\mathrm{I}\right)\left(\mu_{3}-\mathrm{I}\right)_{4}\left\{\mathrm{E}_{2} \mathrm{PH}_{2}\right\}_{6}(\mathrm{E}=\mathrm{S}, \mathrm{Se})\right.$ models.

\begin{tabular}{|c|c|c|c|c|c|c|}
\hline $\begin{array}{l}\text { Model cluster } \\
\text { (label) }\end{array}$ & Sym & $\begin{array}{l}\text { Imag. Freq. } \\
\text { (cm-1) }\end{array}$ & $\begin{array}{c}\Delta \mathrm{E} \\
(\mathrm{eV})\end{array}$ & $\begin{array}{l}\text { Cu-Icenter } \\
\text { (Å) }\end{array}$ & $\begin{array}{l}\text { Cu-I } \text { I }_{\text {cap }} \\
\text { (Å) }\end{array}$ & $\begin{array}{c}\text { Cu-Cu } \\
\text { (Å) }\end{array}$ \\
\hline $\begin{array}{c}{\left[\mathrm{Cu}_{11}\left(\mu_{9}-\mathrm{I}\right)\left(\mu_{3}-\mathrm{I}\right)_{3}\left\{\mathrm{~S}_{2} \mathrm{P}(\mathrm{OH})_{2}\right\}_{6}\right]^{+}} \\
\mathbf{( 1 - S )}\end{array}$ & $C_{3 h}$ & - & - & $\begin{array}{l}6 \times 3.136 \\
3 \times 2.855\end{array}$ & $\begin{array}{l}6 \times 2.684 \\
3 \times 2.640\end{array}$ & $\begin{array}{l}6 \times 4.357 \\
3 \times 3.745 \\
6 \times 3.360 \\
6 \times 3.214 \\
6 \times 3.091\end{array}$ \\
\hline \multirow{2}{*}{$\begin{array}{c}{\left[\mathrm{Cu}_{11}\left(\mu_{9}-\mathrm{I}\right)\left(\mu_{3}-\mathrm{I}\right)_{3}\left\{\mathrm{Se}_{2} \mathrm{P}(\mathrm{OH})_{2}\right\}_{6}\right]^{+}} \\
\mathbf{( 1 - S e )}\end{array}$} & $C_{3 h}$ & $17 i, a^{\prime \prime}$ & 0.005 & $\begin{array}{l}6 \times 3.189 \\
3 \times 2.857\end{array}$ & $\begin{array}{l}6 \times 2.683 \\
3 \times 2.647\end{array}$ & $\begin{array}{l}6 \times 4.414 \\
3 \times 3.834 \\
6 \times 3.362 \\
6 \times 3.287 \\
6 \times 3.139\end{array}$ \\
\hline & $C_{3}$ & - & 0.00 & $\begin{array}{l}3 \times 3.415 \\
3 \times 2.942 \\
3 \times 2.897\end{array}$ & $\begin{array}{l}3 \times 2.723 \\
3 \times 2.659 \\
3 \times 2.641\end{array}$ & $\begin{array}{c}3 \times(4.634 ; 4.150) \\
3 \times 3.839 \\
3 \times(3.423 ; 3.191) \\
3 \times(3.513 ; 3.238) \\
3 \times(3.225 ; 3.060)\end{array}$ \\
\hline 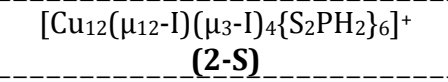 & $T_{d}$ & - & - & $12 \times 3.236$ & $12 \times 2.604$ & $\begin{array}{r}12 \times 3.059 \\
12 \times 3.408\end{array}$ \\
\hline \multirow[b]{2}{*}{$\begin{array}{c}{\left[\mathrm{Cu}_{12}\left(\mu_{12}-\mathrm{I}\right)\left(\mu_{3}-\mathrm{I}\right)_{4}\left\{\mathrm{Se}_{2} \mathrm{PH}_{2}\right\}_{6}\right]^{+}} \\
\mathbf{( 2 - S e )}\end{array}$} & $T_{d}$ & $\begin{array}{l}21 i, t_{2} \\
13 i, t_{1}\end{array}$ & 0.04 & $12 \times 3.308$ & $12 \times 2.596$ & $\begin{array}{l}12 \times 3.174 \\
12 \times 3.439\end{array}$ \\
\hline & $C_{3}$ & - & 0.00 & $\begin{array}{l}3 \times 2.830 \\
3 \times 3.559 \\
3 \times 3.317 \\
3 \times 3.610\end{array}$ & $\begin{array}{l}3 \times 2.581 \\
3 \times 2.585 \\
3 \times 2.598 \\
3 \times 2.660\end{array}$ & $\begin{array}{l}3 \times(2.954 ; 3.195 ; 3.537 ; 3.426) \\
3 \times(3.547 ; 3.435 ; 3.437 ; 3.323)\end{array}$ \\
\hline $\begin{array}{c}{\left[\mathrm{Cu}_{11}\left(\mu_{3}-\mathrm{I}\right)_{3}\left\{\mathrm{~S}_{2} \mathrm{P}(\mathrm{OH})_{2}\right\}_{6}\right]^{2+}} \\
\mathbf{( 3 - S )}\end{array}$ & $C_{3 h}$ & - & - & - & $\begin{array}{l}3 \times 2.568 \\
6 \times 2.625\end{array}$ & $\begin{array}{l}6 \times 4.626 \mathrm{Cu}_{\mathrm{a}}-\mathrm{Cu}_{\mathrm{a}} \\
3 \times 4.096 \mathrm{Cu}_{\mathrm{a}}-\mathrm{Cu}_{\mathrm{a}^{\prime}} \\
6 \times 3.515 \mathrm{Cu}_{\mathrm{a} / \mathrm{a}^{\prime}-\mathrm{Cu}_{\mathrm{b}}} \\
6 \times 3.620 \mathrm{Cu}_{\mathrm{a}} / \mathrm{a}^{\prime}-\mathrm{Cu}_{\mathrm{b}} \\
6 \times 3.231 \mathrm{Cu} \text { a } / \mathrm{a}^{\prime}-\mathrm{Cu} \mathrm{c}\end{array}$ \\
\hline $\begin{array}{c}{\left[\mathrm{Cu}_{11}\left(\mu_{3}-\mathrm{I}\right)_{3}\left\{\mathrm{Se}_{2} \mathrm{P}(\mathrm{OH})_{2}\right\}_{6}\right]^{2+}} \\
\mathbf{( 3 - S e )}\end{array}$ & $C_{3 h}$ & - & - & - & $\begin{array}{l}1 \times 2.560 \\
2 \times 2.621\end{array}$ & $\begin{array}{l}6 \times 4.762 \\
3 \times 4.201 \\
6 \times 3.653 \\
6 \times 3.708 \\
6 \times 3.338\end{array}$ \\
\hline$\left[\mathrm{Cu}_{12}\left(\mu_{3}-\mathrm{I}\right)_{4}\left\{\mathrm{~S}_{2} \mathrm{PH}_{2}\right\}_{6}\right]^{2+}$ & $T_{d}$ & - & - & - & $12 \times 2.577$ & $\begin{array}{l}12 \times 3.483 \mathrm{Cu}_{1}-\mathrm{Cu}_{1} \\
12 \times 3.652 \mathrm{Cu}_{1}-\mathrm{Cu}_{2}\end{array}$ \\
\hline $\begin{array}{c}{\left[\mathrm{Cu}_{12}\left(\mu_{3}-\mathrm{I}\right)_{4}\left\{\mathrm{Se}_{2} \mathrm{PH}_{2}\right\}_{6}\right]^{2+}} \\
\text { (4-Se) }\end{array}$ & $T_{d}$ & - & - & - & $12 \times 2.571$ & $\begin{array}{l}12 \times 3.664 \\
12 \times 3.727\end{array}$ \\
\hline
\end{tabular}


Not considering the bonds with the central iodide, all the metal atoms are in an approximate trigonal-planar configuration, the $\mathrm{Cu}_{\mathrm{a}}$ and $\mathrm{Cu}_{\mathrm{b}}$ atoms being bonded to two chalcogens and one capping iodide and the $\mathrm{Cu}_{c}$ atoms to three chalcogens. It is noteworthy that in the case of the di-seleno species, geometry optimizations with the $C_{3 h}$ symmetry constraint does not lead to an energy minimum at our level of theory, but rather to a transition state showing a single (small) imaginary frequency $\left(17 i \mathrm{~cm}^{-1}\right)$. A true energy minimum was obtained reducing symmetry constraint to $C_{3}$, corresponding to a slight displacement of the encapsulated iodide along the $C_{3}$ axis away from the center of the metallic cage. This leads to two different $\mathrm{Cu}_{\mathrm{c}}$-I distances of 3.610 and 3.924 $\AA$ (both equal to $3.750 \AA$ when $C_{3 h}$ symmetry constraint is assumed). The symmetry lowering is associated to a very small stabilization energy $(\Delta \mathrm{E}=0.004 \mathrm{eV})$, so that the encapsulated iodide is nearly free to move along the $C_{3}$ axis with quite large displacements. As a consequence, in the following the discussion will be mainly based in on the ideal cluster with $C_{3 h}$ symmetry.

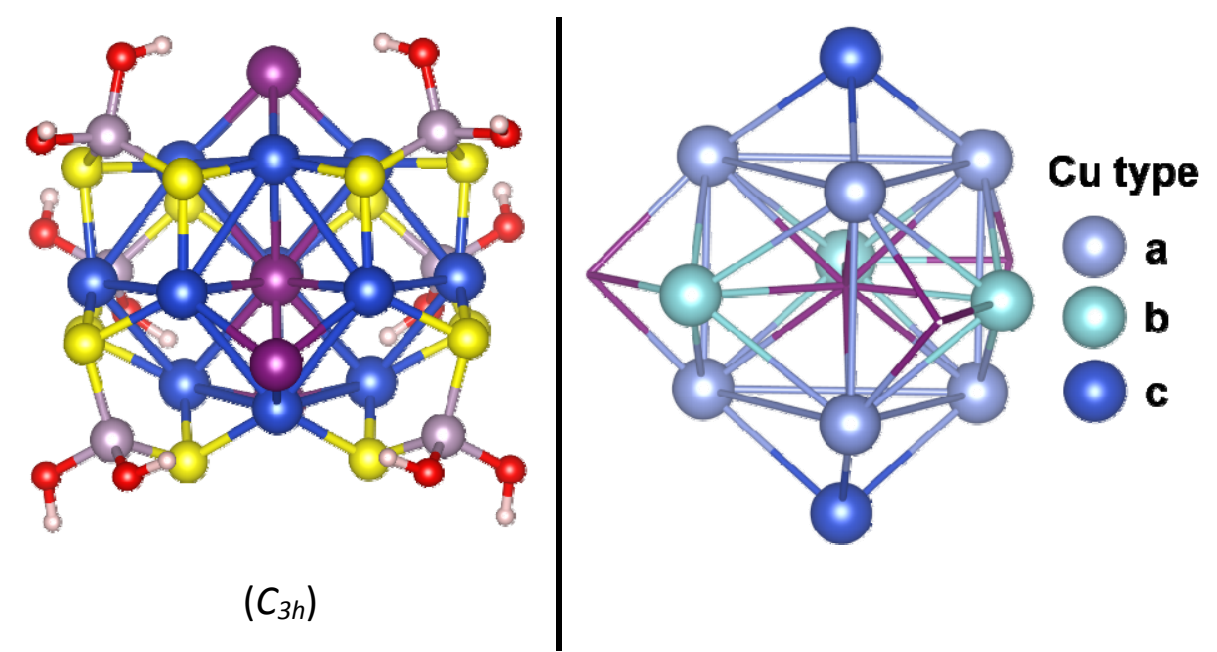

Figure 1. Optimized structure of the 1-S model (left) and its $\mathrm{Cu}_{11}\left(\mu_{9}-\mathrm{I}\right)\left(\mu_{3}-\mathrm{I}\right)$ core (right).

The most significant structural data of the optimized geometries of the dodecanuclear models $\left[\mathrm{Cu}_{12}\left(\mu_{12}-\mathrm{I}\right)\left(\mu_{3}-\mathrm{I}\right)_{4}\left\{\mathrm{E}_{2} \mathrm{PH}_{2}\right\}_{6}\right]^{+}(\mathrm{E}=\mathrm{S}, \mathbf{2 - S}$; Se, 2-Se) are given in Table 2. They were first considered in their ideal $T_{d}$ symmetry (Figure 2). Their metallic skeleton can be described as a cuboctahedron (more precisely a cantellated tetrahedron), with two different $\mathrm{Cu}-\mathrm{Cu}$ edges. Thus, the encapsulated iodide is equally bonded to the twelve metal atoms and the $\mathrm{Cu}_{12} \mathrm{I}$ core is of idealized $O_{h}$ symmetry. The 
$\mathrm{Cu}-\left(\mu_{12}-\mathrm{I}\right)$ distances are slightly larger than the $\mathrm{Cu}-\left(\mu_{9}-\mathrm{I}\right)$ distances found in the undecanuclear series (Table 2). Moreover, the computed $\mathrm{Cu}-\left(\mu_{12}-\mathrm{I}\right)$ bond lengths $(12 \times$ $3.236 \AA$; $\mathrm{E}=\mathrm{S}$ ) fit nicely with that observed in the X-ray structure of the related $[\mathrm{PyH}]\left[\left\{\mathrm{TpMo}\left(\mu_{3}-\mathrm{S}\right)_{4} \mathrm{Cu}_{3}\right\}_{4}\left(\mu_{12}-\mathrm{I}\right)\right]\left[\left\{\mathrm{TpMo}\left(\mu_{3}-\mathrm{S}\right)\right\}_{4} \mathrm{Cu}_{12}\left(\mu_{12}-\mathrm{I}\right)\right] \quad(12 \times 3.138-3.280 \AA$, avg. $3.195 \AA$ A $).{ }^{27}$ Similarly, the optimized Cu-Cu distances $(12 \times 3.059 \AA$ and $12 \times 3.408 \AA)$ are in good agreement with the experimental ones $(12 \times 3.098-3.144$, avg. $3.122 \AA$, and $12 \times$ 3.214-3.309, avg. $3.269 \AA$ A). ${ }^{27}$ The square faces of the metallic core are bridged by a dichalcogenophosphate ligand $\left(\mu_{2}, \mu_{2}\right)$ and four out of the eight triangular faces are capped by a $\mu_{3}$-iodide (Figure 2). As a result, each metal atom is bonded to one iodine and two chalcogen atoms in a slightly pyramidalized coordination mode (not considering bonding with the encapsulated iodine).

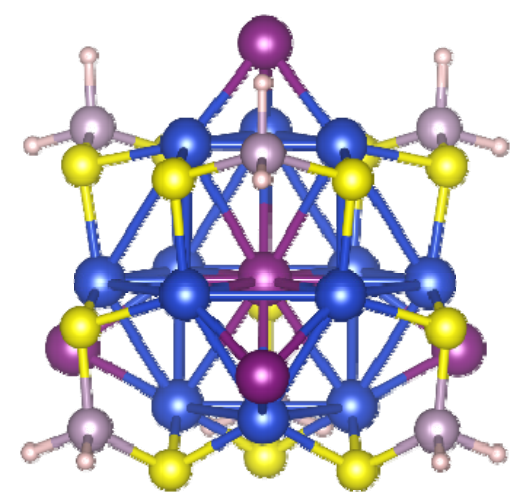

$\left(T_{d}\right)$

Figure 2. Optimized structure of the $\left[\mathrm{Cu}_{12}\left(\mu_{12}-\mathrm{I}\right)\left(\mu_{3}-\mathrm{I}\right)_{4}\left\{\mathrm{~S}_{2} \mathrm{PH}_{2}\right\}_{6}\right]^{+}$(2-S) model.

As in the case of its undecanuclear relative, the diselenophosphate species was not found to be an energy minimum in its highest ( $\left.T_{d}\right)$ symmetry possible (Table 2). The minimum on the potential energy surface corresponds to a slightly distorted structure of $C_{3}$ symmetry. Furthermore, in analogy with the undecanuclear diselenophosphate cluster, the energy difference is small $(\Delta \mathrm{E}=0.04 \mathrm{eV})$, suggesting an easy displacement of the encapsulated atom around the center of the cuboctahedral cage. In the followings, the discussion will be mainly based on the ideal cluster with $T_{d}$ symmetry.

\section{Bonding analysis of the computed models}

Considering first the clusters as empty in both species (no encapsulated atom), all the copper(I) centers lie in an approximate trigonal-planar coordination mode. Therefore, each metal atom is a 16-electron center and bears an accepting orbital of 
large $4 p_{z}$ character, which points towards the center of the cage. In the whole cage, the individual $4 \mathrm{p}_{\mathrm{z}}$-type orbitals give rise to a set of 11 or 12 empty combinations, at least four of which have the proper symmetry to interact in a bonding way with the occupied $5 s$ and $5 p$ AOs of iodide. This situation is sketched in Figure 3 in the case of a $\left[\mathrm{Cu}_{12}\left(\mu_{12}-\right.\right.$ I) $\left.\left(\mu_{3}-\mathrm{I}\right)_{4}\left\{\mathrm{E}_{2} \mathrm{POR}_{2}\right\}_{6}\right]^{+}\left(\mathrm{E}=\mathrm{S}\right.$, Se) cluster, assuming $O_{h}$ pseudo-symmetry. It should be noted that the weak destabilizing interaction occurring between some of the $3 \mathrm{~d}$-block combinations and the iodide AOs is not considered in Figure 3. The computed KohnSham orbital diagrams of our undeca- and dodeca-nuclear models are consistent with this qualitative model. Those of $\left[\mathrm{Cu}_{11}\left(\mu_{9}-\mathrm{I}\right)\left(\mu_{3}-\mathrm{I}\right)_{3}\left\{\mathrm{Se} 2 \mathrm{P}(\mathrm{OH})_{2}\right\}_{6}\right]^{+}$and $\left[\mathrm{Cu}_{12}\left(\mu_{12}-\mathrm{I}\right)\left(\mu_{3^{-}}\right.\right.$ I) $\left.{ }_{4}\left\{\mathrm{~S}_{2} \mathrm{POH}_{2}\right\}_{6}\right]^{+}$are shown in Figure 4 . Those of their homologs are provided in the SI (Figures S1 and S2).

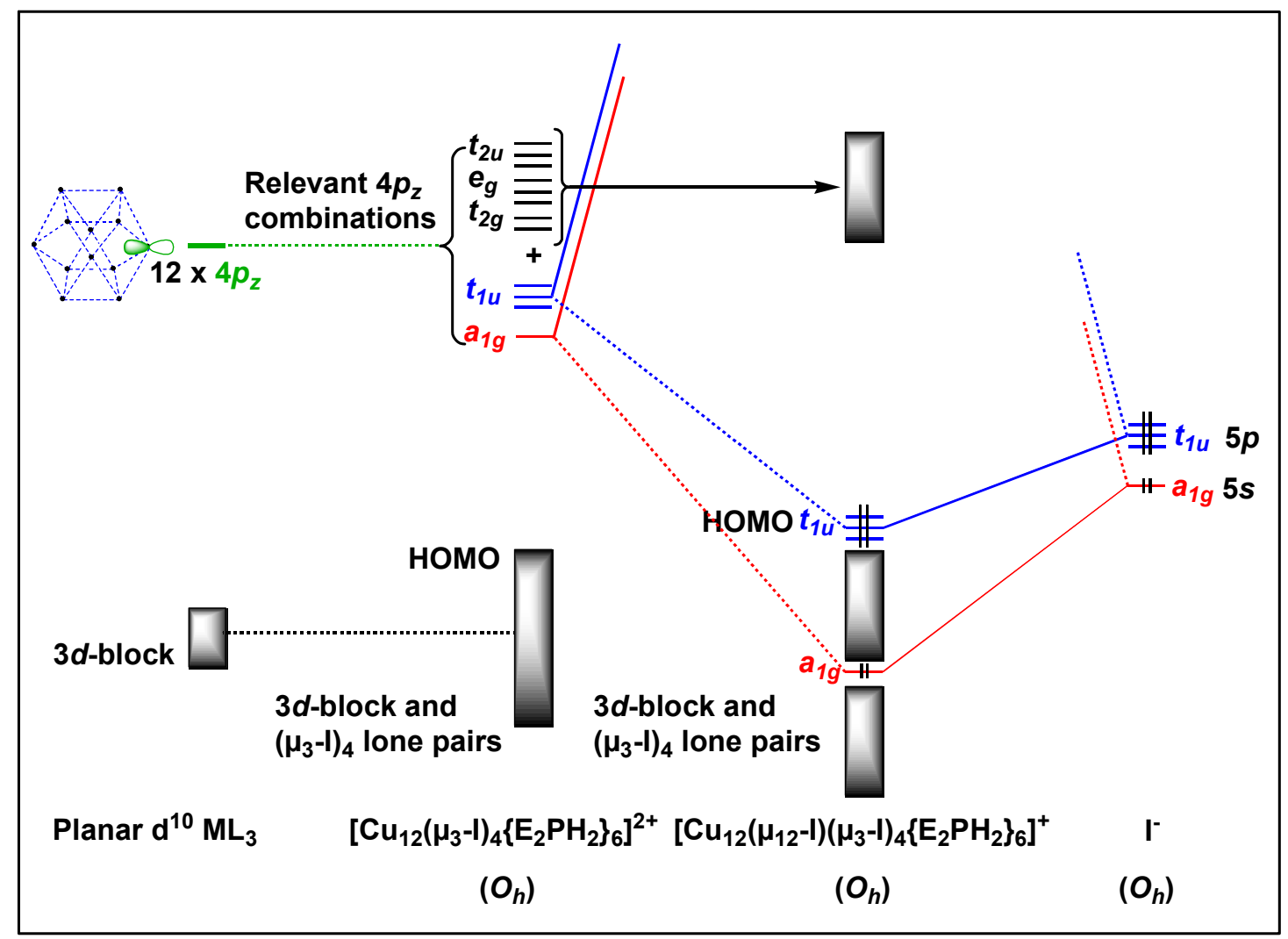

Figure 3. Qualitative MO diagram illustrating the interaction between the empty cage $\left[\mathrm{Cu}_{12}\left(\mu_{3}-\mathrm{I}\right)_{4}\left\{\mathrm{E}_{2} \mathrm{POR}_{2}\right\}_{6}\right]^{2+}(\mathrm{E}=\mathrm{S}, \mathrm{Se})$ and its I- host in the $\left[\mathrm{Cu}_{12}\left(\mu_{12}-\mathrm{I}\right)\left(\mu_{3}-\mathrm{I}\right)_{4}\left\{\mathrm{E}_{2} \mathrm{POR}_{2}\right\}_{6}\right]^{+}(\mathrm{E}$ $=\mathrm{S}, \mathrm{Se}$ ) cluster in the ideal $O_{h}$ pseudo-symmetry. 
A more quantitative bonding analysis can be performed in terms of bonding energy (BE), dissociation energy (DE), distortion energy of the cluster cage $\left(\Delta \mathrm{E}_{\mathrm{dist}}\right)$, natural orbitals and Wiberg indices. The bonding energy can be calculated as:

$B E=E_{2}+E_{\text {Hents }}-E_{\text {tie }}$

Where the subindexes $H$ and $G$ refer to the host and guest, respectively, i. $e_{\text {., }} E_{c}$ is the energy of the free ion, $E_{\text {स }}$ optimized when the ion is inside the cluster cage and $E_{\text {sis }}$ is the energy of the whole cluster at its optimized geometry. The dissociation energy is:

$D E=E_{G}+E_{H Q L_{\square}}-E_{E G}^{i}$

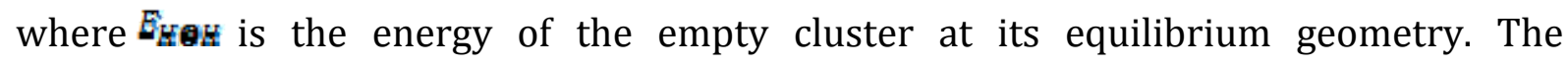
difference between $\mathrm{BE}$ and $\mathrm{DE}\left(\Delta \mathrm{E}_{\mathrm{Dist}}\right)$ is the amount of energy required to distort the relaxed empty cage to the geometry adopted when the anion is inside the cage:

$\Delta \mathrm{E}_{\mathrm{Dist}}=B E-D E$

As one can see in Table 3, the BE values are nearly the same $(\sim 8 \mathrm{eV})$, irrespective of the nature of $\mathrm{E}(\mathrm{S} v s . \mathrm{Se})$ and the nuclearity of the metallic cage $\left(\mathrm{Cu}_{11} v s . \mathrm{Cu}_{12}\right)$. The same conclusion can be established for DE. However, there is a significant difference in $\Delta \mathrm{E}_{\text {Dist }}$ when going from the $\mathrm{S}$ to $\mathrm{Se}\left(\sim 15 \%\right.$ for $\mathrm{Cu}_{11}$ and $\sim 20 \%$ for $\left.\mathrm{Cu}_{12}\right)$, whereas the nuclearity does not impact dramatically this energy. 

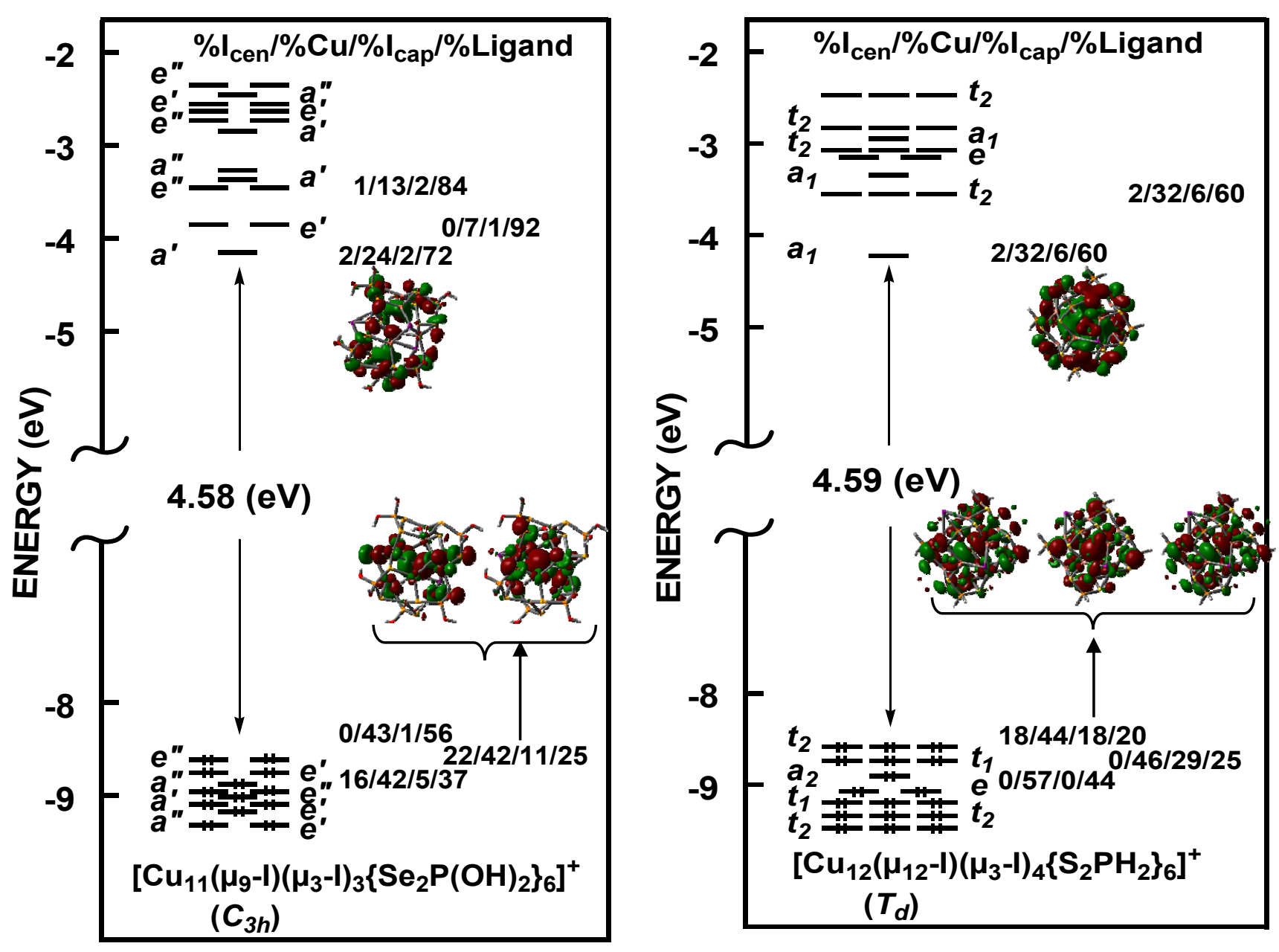

Figure 4. Kohn-Sham orbital diagrams of $\left[\mathrm{Cu}_{11}\left(\mu_{9}-\mathrm{I}\right)\left(\mu_{3}-\mathrm{I}\right)_{3}\left\{\mathrm{Se}_{2} \mathrm{P}(\mathrm{OH})_{2}\right\}_{6}\right]^{+}$(left) and $\left[\mathrm{Cu}_{12}\left(\mu_{12}-\mathrm{I}\right)\left(\mu_{3}-\mathrm{I}\right)_{4}\left\{\mathrm{~S}_{2} \mathrm{PH}_{2}\right\}_{6}\right]^{+}$(right).

The rather negative NAO charges of the central iodide and the moderate values of the sums of the $\mathrm{Cu}-\mathrm{I}$ Wiberg indices are consistent with the existence of an iono-covalent bond. Furthermore, the sum of $\mathrm{Cu}$-I Wiberg indices decreases when going from $\mathrm{Cu}_{11}$ to $\mathrm{Cu}_{12}$ clusters, and this is accompanied by a slight increase of the iodine negative charge, suggesting that the ionic character of the bonding increases with the connectivity of the central halide. It is noteworthy that in the undecanuclear clusters, independently of the ligand, the $\mathrm{Cu}_{\mathrm{b}}-\mathrm{I}_{\text {center }}$ Wiberg indices are twice larger than the $\mathrm{Cu}_{\mathrm{a}}-\mathrm{I}_{\text {center }}$ ones $(\sim 0.06 v s$. 0.03). This result is in agreement with the shortening of the $\mathrm{Cu}-\mathrm{I}_{\text {center }}$ distances when going from $\mathrm{Cu}_{\mathrm{a}}-\mathrm{I}_{\mathrm{center}}$ to $\mathrm{Cu}_{\mathrm{b}}-\mathrm{I}_{\text {center. }}$. Finally, the metallic core contracts itself by $\mathrm{ca} 25 \%$ when going from the empty to the iodine-centered cluster. 
Table 3. Relevant Bonding Parameters Computed for Clusters 1-S, 1-Se, 2-S and 2-Se.

\begin{tabular}{|c|c|c|c|c|c|c|c|c|c|}
\hline Model clusters & Sym. & $\begin{array}{l}\text { HOMO- } \\
\text { LUMO gap } \\
\text { (eV) }\end{array}$ & $\begin{array}{l}\mathrm{BE} \\
(\mathrm{eV})\end{array}$ & $\begin{array}{l}\text { DE } \\
(\mathrm{eV})\end{array}$ & $\begin{array}{l}\Delta \mathrm{E}_{\text {dist }} \\
(\mathrm{eV})\end{array}$ & $\begin{array}{c}\text { Sum of } \\
\text { Cu-Icap } \\
\text { Wiberg } \\
\text { indices }\end{array}$ & $\begin{array}{c}\text { Sum of Cu- } \\
\text { Icenter } \\
\text { Wiberg } \\
\text { indices } \\
\end{array}$ & $\begin{array}{l}\text { NAO net } \\
\text { charge of } \\
\text { I }_{\text {center }}\end{array}$ & $\begin{array}{l}\text { Population } \\
\text { of Icenter }\end{array}$ \\
\hline $1-S$ & $C_{3 h}$ & 5.19 & 8.21 & 7.65 & 0.56 & 0.62 & $\begin{array}{c}0.41 \\
3 \times 0.0632 \\
6 \times 0.0332 \\
0.41\end{array}$ & -0.75 & $\mathrm{~s}^{1.92} \mathrm{p}^{5.81} \mathrm{~d}^{0.01}$ \\
\hline 1-Se & $C_{3 h}$ & 4.58 & 8.17 & 7.51 & 0.66 & 0.59 & $\begin{array}{c}0.41 \\
3 \times 0.0684 \\
6 \times 0.0315\end{array}$ & -0.75 & $\mathrm{~s}^{1.92} \mathrm{p}^{5.81} \mathrm{~d}^{0.01}$ \\
\hline $2-S$ & $T_{d}$ & 4.59 & 8.18 & 7.61 & 0.57 & 0.74 & $\begin{array}{c}0.37 \\
12 \times 0.0307\end{array}$ & -0.76 & $\mathrm{~s}^{1.94} \mathrm{p}^{5.81} \mathrm{~d}^{0.01}$ \\
\hline 2-Se & $T_{d}$ & 4.01 & 8.00 & 7.29 & 0.71 & 0.72 & $\begin{array}{c}0.35 \\
12 \times 0.0295\end{array}$ & -0.76 & $\mathrm{~s}^{1.94} \mathrm{p}^{5.81} \mathrm{~d}^{0.01}$ \\
\hline
\end{tabular}

\section{Synthesis and characterization of $\left[\mathrm{Cu}_{11}\left(\mu_{9}-I\right)\left(\mu_{3}-I\right)_{3}\left\{\mathrm{Se}_{2} \mathrm{P}\left(\mathrm{O}^{i} \mathrm{Pr}\right)_{2}\right\}_{6}\right](\mathrm{OH})$ (1-Se-a), and $\left[C u_{11}\left(\mu_{9}-I\right)\left(\mu_{3}-I\right)_{3}\left(S_{2} P P h_{2}\right)_{6}\right]\left(P F_{6}\right)(1-S e-b)$}

Treatment of copper salts, diselenophosph(in)ates, and $\mathrm{Bu}_{4} \mathrm{NI}$ in a 11: 6: 5 ratio affords cationic clusters of the type, $\left[\mathrm{Cu}_{11}\left(\mu_{9}-\mathrm{I}\right)\left(\mu_{3}-\mathrm{I}\right)_{3}\left(\mathrm{Se}_{2} \mathrm{PR}_{2}\right)_{6}\right]^{+}\left(\mathrm{R}=\mathrm{O}^{\mathrm{i} P r}, \mathbf{1 - S e}-\mathbf{a}\right.$; Ph, 1Se-b), in good yield. In compound 1-Se-a, a single phosphorus resonance centered at $74.3 \mathrm{ppm}$, flanked by two sets of selenium satellites ( $U_{\mathrm{PSe}}=664.8$ and $661.7 \mathrm{~Hz}$ ), is observed in solution ${ }^{31} \mathrm{P}\left\{{ }^{1} \mathrm{H}\right\}$ NMR spectrum. Two inequivalent Se atoms of the diselenophosphate ligand revealed from ${ }^{31} \mathrm{P}$ NMR spectroscopy are the reminiscence of a virtual $C_{3 h}$ symmetry of the $\mathrm{Cu}_{11}$ cluster, ${ }^{13}$ which is echoed by the observed two multiplets of methine $(\mathrm{CH})$ protons of the isopropyl groups in the ${ }^{1} \mathrm{H}$ NMR spectrum as well as two unresolved doublet peaks in the ${ }^{77} \mathrm{Se}\left\{{ }^{1} \mathrm{H}\right\}$ NMR spectrum. ${ }^{13}$ A similar ${ }^{31} \mathrm{P}$ NMR pattern was observed in 1-Se-b. Unfortunately no signals were detected in the ${ }^{77} \mathrm{Se}$ NMR spectrum of 1-Se-b at ambient temperature, which could be due to the lability of $\mathrm{Cu}$-Se bonds. Owing to its poor solubility in $\mathrm{CH}_{2} \mathrm{Cl}_{2}$, the low temperature ${ }^{77} \mathrm{Se} \mathrm{NMR}$ experiments were not recorded. Its composition is further confirmed by the positive ESIMS spectrum in $\mathrm{CH}_{2} \mathrm{Cl}_{2}$ depicted in Figure 5. Aside from the most intense band centered at 3048.6, which corresponds to the molecular ion peak of $\left[\mathrm{Cu}_{11}\left(\mu_{9}-\mathrm{I}\right)\left(\mu_{3}-\right.\right.$ I) $\left.{ }_{3}\left\{\mathrm{Se}_{2} \mathrm{P}\left(\mathrm{O}^{\mathrm{i} P r}\right)_{2}\right\}_{6}\right]^{+}$(calcd 3049.3 ), two bands centered at 2387.5 and 3240.0 are also detected. While the peak at m/z 2387.5 can be reasonably attributed to the chloridecentered $\mathrm{Cu}_{8}$ species, $\left[\mathrm{Cu}_{8}\left(\mu_{8}-\mathrm{Cl}\right)\left\{\mathrm{Se}_{2} \mathrm{P}\left(\mathrm{O}^{\mathrm{i} P r}\right)_{2}\right\}_{6}\right]^{+}$(Calcd 2287.8), generated from the ionization of 1-Se-a in methylene chloride, the band at m/z 3240.0 does match well with a species $\left[\mathrm{Cu}_{12}(\mathrm{I})_{5}\left\{\mathrm{Se}_{2} \mathrm{P}\left(\mathrm{O}^{\mathrm{P} P r}\right)_{2}\right\}_{6}\right]^{+}$, whose formula weight is 3239.1 . 
A thermal ellipsoid drawing of the cationic cluster 1-Se-a is depicted in Figure 5(a) with a schematic representation of a pentacapped trigonal prismatic $\mathrm{Cu}_{11}\left(\mu_{9}\right.$-I) core in Figure $5(b)$.

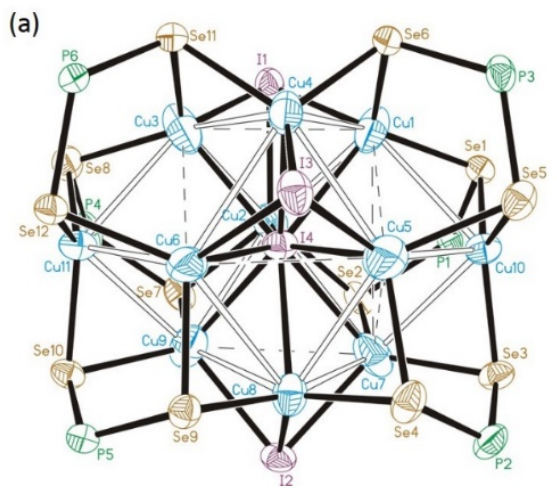

(b)

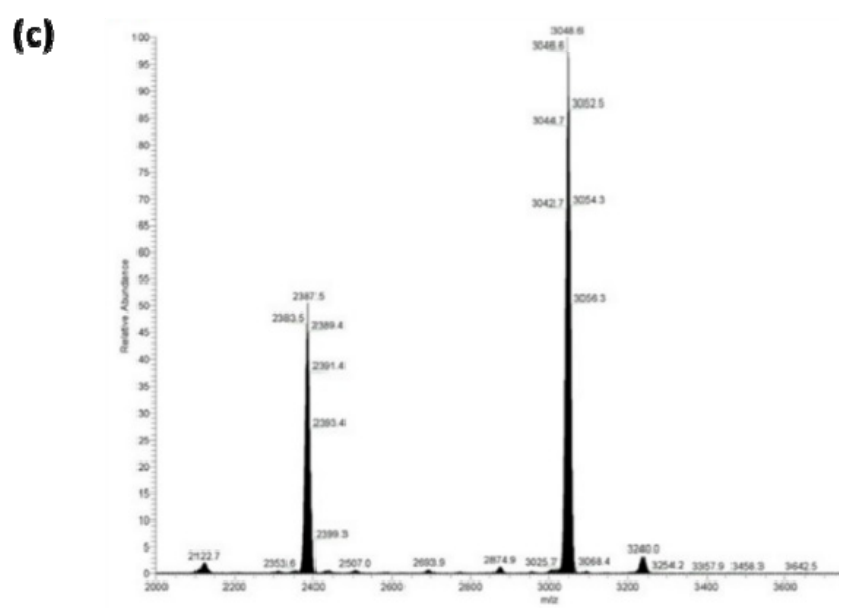

Figure 5. (a) ORTEP drawing of $\left[\mathrm{Cu}_{11}\left(\mu_{9}-\mathrm{I}\right)\left(\mu_{3}-\mathrm{I}\right)_{3}\left\{\mathrm{Se}_{2} \mathrm{P}\left(\mathrm{O}^{i} \mathrm{Pr}\right)_{2}\right\}_{6}\right]^{+}$in 1-Se-a $(30 \%$ thermal ellipsoid) with isopropoxy groups omitted for clarity; (b) Representation of the pentacapped trigonal prismatic $\mathrm{Cu}_{11}\left(\mu_{9}-\mathrm{I}\right)$ core. I4-Cu5: 2.645(3), I4-Cu2: 2.723(3), I4Cu8: 2.795(2), I4-Cu9: 2.833(3), I4-Cu4: 2.862(2), I4-Cu3: 2.865(3), I4-Cu6: 2.876(3), I4Cu1: 2.949(3), I4-Cu7: 3.070(3) Å. (c) A positive ESI-MS spectrum of 1-Se-a.

The cluster cation has an idealized $C_{3 h}$ symmetry and is isostructural to its silver analogue, $\left[\mathrm{Ag}_{11}\left(\mu_{9}-\mathrm{I}\right)\left(\mu_{3}-\mathrm{I}\right)_{3}\left\{\mathrm{Se}{ }_{2} \mathrm{P}\left(\mathrm{O}^{\mathrm{i} P r}\right)_{2}\right\}_{6}\right]^{+}, 25$ and with our computed model clusters 1-S and 1-Se. Consistently, two kinds of iodide ion $\left(\mu_{9}\right.$ and $\left.\mu_{3}\right)$ can be found in both structures and the one located at the cluster center (I4) connects to the peripheral copper ions, except the two on the $C_{3}$ axis (Cu10 and $\mathrm{Cu} 11$ ), in the range 2.645(3) $3.070(3) \AA$ in the case of $\mathbf{1}$-Se-a. It appears that the size of $\mathrm{Cu}_{11}$ core in cluster $\mathbf{1}$-Se-b is larger than that of 1-Se-a as revealed from the larger $\mu_{9}$-I-Cu distances lying in the range $2.803(2)-3.242(2) \AA$. In the related computed $C_{3 h}$ model 1-Se, the optimized Cu-I $\mathrm{I}_{\text {center }}$ bond lengths are in also within this range: $6 \times 3.189$ and $3 \times 2.857 \AA$ (Table 2). The three 
other iodides, each capping a $\mathrm{Cu}_{3}$ triangular face, average $2.637(2) \AA ̊$ in 1-Se-a $(2.587(2)$ $\AA ̊$ in 1-Se-b). In the computed homolog 1-Se, the $\mathrm{Cu}-\mathrm{I}_{\text {cap }}$ distances are $6 \times 2.683$ and $3 \times$ 2.647 and, once again, are in good agreement with the experimental ones.

\section{Optical Properties}

The ambient temperature UV-Vis absorption spectrum of 1-Se-a in $\mathrm{CH}_{2} \mathrm{Cl}_{2}$ (see green line in Figure 6) displays a shoulder peak at approximately $402 \mathrm{~nm}$ (molar absorptivity $\sim 10,000 \mathrm{dm}^{3} \mathrm{~mol}^{-1} \mathrm{~cm}^{-1}$ ) and a more intense band extending well into the UV region, with a maximum below $330 \mathrm{~nm}$. While the low energy peak is attributed to a charge transfer within the cluster cage, the strong absorption in the UV region likely originates from ligand-centered transitions. A structureless emission band at $77 \mathrm{~K}$ (excited at $435 \mathrm{~nm}$ ) centered at $766 \mathrm{~nm}$ is also depicted in Figure 6. In methylene chloride glass, the emission slightly shifts to $745 \mathrm{~nm}$. Large Stokes shift $\left(\sim 11,800 \mathrm{~cm}^{-1}\right)$ suggests that the red emission originates from a spin-forbidden triplet excited state, this hypothesis being further confirmed by the life time of the excited state of the cluster 1Se-b in the microsecond region (Table S1).

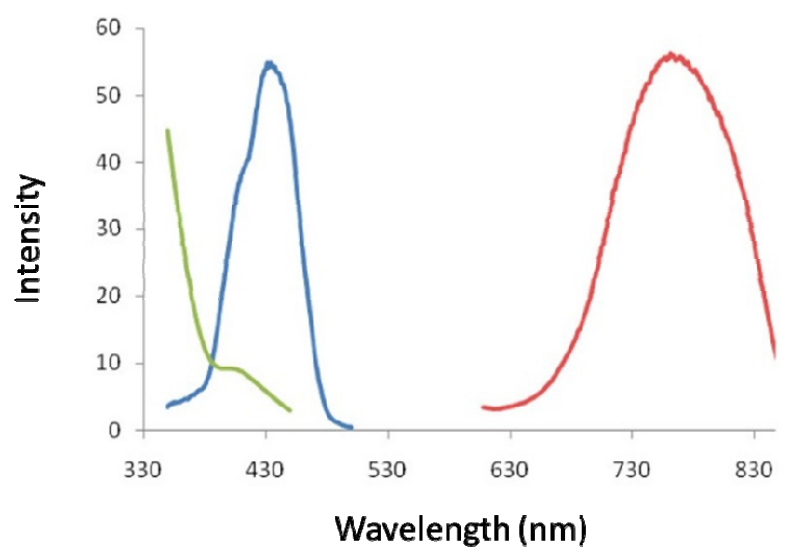

Figure 6. Absorption (RT), excitation (77 K), and emission (77 K) spectra of 1-Se-a in solid state.

TD-DFT computations have been performed on our model compounds in order to assign the band absorption of 1-Se-a and 1-Se-b. In general terms, despite a strong overestimation of the vertical electronic transitions, the trend between $\mathrm{E}=\mathrm{S}$ and $\mathrm{E}=\mathrm{Se}$ is well reproduced. Indeed, experimentally, the absorption bands of 
$\left[\mathrm{Cu}_{11}\left(\mu_{9}-\mathrm{I}\right)\left(\mu_{3}-\mathrm{I}\right)_{3}\left\{\mathrm{Se}_{2} \mathrm{P}\left(\mathrm{O}^{\mathrm{iPr}}\right)_{2}\right\}_{6}\right](\mathrm{OH})$ and $\left[\mathrm{Cu}_{11}\left(\mu_{9}-\mathrm{I}\right)\left(\mu_{3}-\mathrm{I}\right)_{3}\left\{\mathrm{~S}_{2} \mathrm{P}\left(\mathrm{O}^{\mathrm{P} P r}\right)_{2}\right\}_{6}\right](\mathrm{OH})$ fall around 402 and $380 \mathrm{~nm}$ (respectively 3.08 and $3.26 \mathrm{eV}$ ). The largest wavelength transitions are computed at 328 and $290 \mathrm{~nm}$ (3.78 and $4.27 \mathrm{eV}$ ) for, E= Se and $\mathrm{S}$, respectively with an overall overestimation of about $0.85 \mathrm{eV}$ (Table 4). The experimental peak can be assigned to a transition from the degenerate HOMO and HOMO-1 to the LUMO for $\mathrm{E}=\mathrm{S}$. For $\mathrm{E}=\mathrm{Se}$, the same excitation corresponds to a transition from the HOMO-2 and HOMO-3 to the LUMO. From the frontier orbitals plots and MO compositions (Figure 4) one can see that in both cases the occupied orbitals are mainly localized on the central iodide ( $5 p$ orbitals), capping iodide and the metallic architecture, whereas the LUMO is strongly localized on the ligands and on the metallic architecture. In addition, there is another excitation of very similar charge transfer character which occurs at a slightly lower wavelength and which corresponds to a HOMO-5 to LUMO transition in both compounds.

Table 4. TD-DFT and Experimental absorption energies and wavelengths of the undecanuclear clusters.

\begin{tabular}{|c|c|c|c|c|}
\hline \multirow{2}{*}{ Compound } & \multicolumn{2}{|c|}{ Exp.a } & \multicolumn{2}{|c|}{ TD-DFT' } \\
\hline & $(\mathrm{eV})$ & $(\mathrm{nm})$ & $(\mathrm{eV})$ & $(\mathrm{nm})$ \\
\hline $1-\mathbf{S}^{55}$ & 3.26 & 380 & 4.27 & 290 \\
\hline 1-Se & 3.08 & 402 & 3.78 & 328 \\
\hline $2-S$ & - & & 3.73 & 332 \\
\hline 2-Se & - & & 3.21 & 386 \\
\hline$\left[\operatorname{Ag}_{12}\left(\mu_{12}-I\right)\left(\mu_{3}-I\right)_{4}\left\{S_{2} P\left(C_{2} C H_{2} P h\right)_{2}\right\}_{6}\right]^{+26}$ & 2.90 & 428 & 3.92 & 316 \\
\hline Experimental compounds: & $\overline{\left(\mu_{9}-I\right.}$ & $-\mathrm{I})_{3}\{\mathrm{Se}$ & $\overline{\left.\left.\mathrm{Pr})_{2}\right\}_{6}\right]}$ & ar \\
\hline$\left.\left(\mu_{9}-\mathrm{I}\right)\left(\mu_{3}-\mathrm{I}\right)_{3}\left\{\mathrm{~S}_{2} \mathrm{P}\left(\mathrm{O}^{\mathrm{i} P r}\right)_{2}\right\}_{6}\right](\mathrm{OH}) \cdot$ b Mod & {$\left[\mathrm{Cu}_{1}\right.$} & ( & $(\mathrm{OH})_{2}$ & $\mathrm{Cu}_{11}(\mu$ \\
\hline I) $\left.\left(\mu_{3}-\mathrm{I}\right)_{3}\left\{\mathrm{Se}_{2} \mathrm{P}(\mathrm{OH})_{2}\right\}_{6}\right]^{+},\left[\mathrm{Cu}_{12}\left(\mu_{12}-\mathrm{I}\right)\left(\mu_{3}-\mathrm{I}\right)_{4}\{\mathrm{~S}\right.$ & $\left.[2\}_{6}\right]^{+}$ & $\mathrm{Cu}_{12}$ & $\left.\mu_{3}-I\right)$ & $\left.[2\}_{6}\right]^{+}$ \\
\hline
\end{tabular}

TD-DFT computations have also been performed on the dodecanuclear model clusters. It turns out that for $\mathrm{E}=\mathrm{S}$, an excitation occurs at $3.73 \mathrm{eV}(332 \mathrm{~nm})$ which can be described as a transition from the highest occupied degenerate $t_{2}$ orbitals to the LUMO. In this case the charge transfer can be described as an admixture of XLCT (halogen to ligand) and MLCT (metal to ligand). When $\mathrm{E}=\mathrm{Se}$, the first excitation is computed at 3.21 $\mathrm{eV}(386 \mathrm{~nm})$ and the charge transfer is similar, this time involving the degenerate HOMO-3, HOMO-4, HOMO-5 $t_{2}$ orbitals and the LUMO. For instance, the computed 
optical properties for $\mathrm{Ag}_{11}\left(\mu_{9}-\mathrm{Se}\right)\left(\mu_{3}-\mathrm{X}\right)\left(\mathrm{Se}{ }_{2} \mathrm{P}(\mathrm{OH})_{2}\right]_{6}(\mathrm{X}=\mathrm{I}, \mathrm{Br})$ fit nicely the experimental ones. 53

In order to model the phosphorescence spectra of the clusters, the first triplet excited state has been investigated using the unrestricted Kohn-Sham method. Upon optimization, frequency calculations have been performed in order to get the normal modes in the excited state. The electronic emission wavelengths for the $\operatorname{Cu}_{11}\left(\mu_{9}-\mathrm{I}\right)$ clusters have been calculated at 424 and $555 \mathrm{~nm}(2.92$ and $2.23 \mathrm{eV}$ ) for $\mathrm{E}=\mathrm{S}$ and Se, respectively. It is important to mention that once again the calculated trend for both dichalcogeno ligands agrees with the observed phosphorescence wavelengths (635 and $745 \mathrm{~nm}$, for E= S and Se, respectively). ${ }^{55,56}$ These results lead to a shift between observed and computed phosphorescence wavelengths corresponding to 0.97 and $0.57 \mathrm{eV}$, for $\mathrm{E}=$ $\mathrm{S}$ and Se, respectively. Furthermore the computed electronic phosphorescence energies are overestimating the experimental ones with the same order of magnitude than in the case of absorption for both ligands.

On these grounds, in order to simulate the phosphorescence spectra of both clusters, vibrational contributions to electronic transitions have been taken into account. In principle the elimination of vibronic contributions issuing from low-frequency normal modes discussed above might affect the shape of the simulated spectra. However, this approximation can be safely employed in the present context since the limited resolution of experimental spectra masks the fine tuning by low-frequency modes under the overall Gaussian shape, whose width is mainly determined by progressions of higher frequency modes. As one can see in Figure 7, the simulated phosphorescence spectra fit nicely the experimental ones upon correction of the energy shift coming from the mentioned limited accuracy of electronic TD-DFT transitions. The Gaussian shape is well reproduced in the simulation and is fully explained in terms of the so-called shift-vector, which corresponds to the gradient of the final state at the geometry of the initial state projected onto the normal modes of the initial state. $38,41,44,57-60$ 


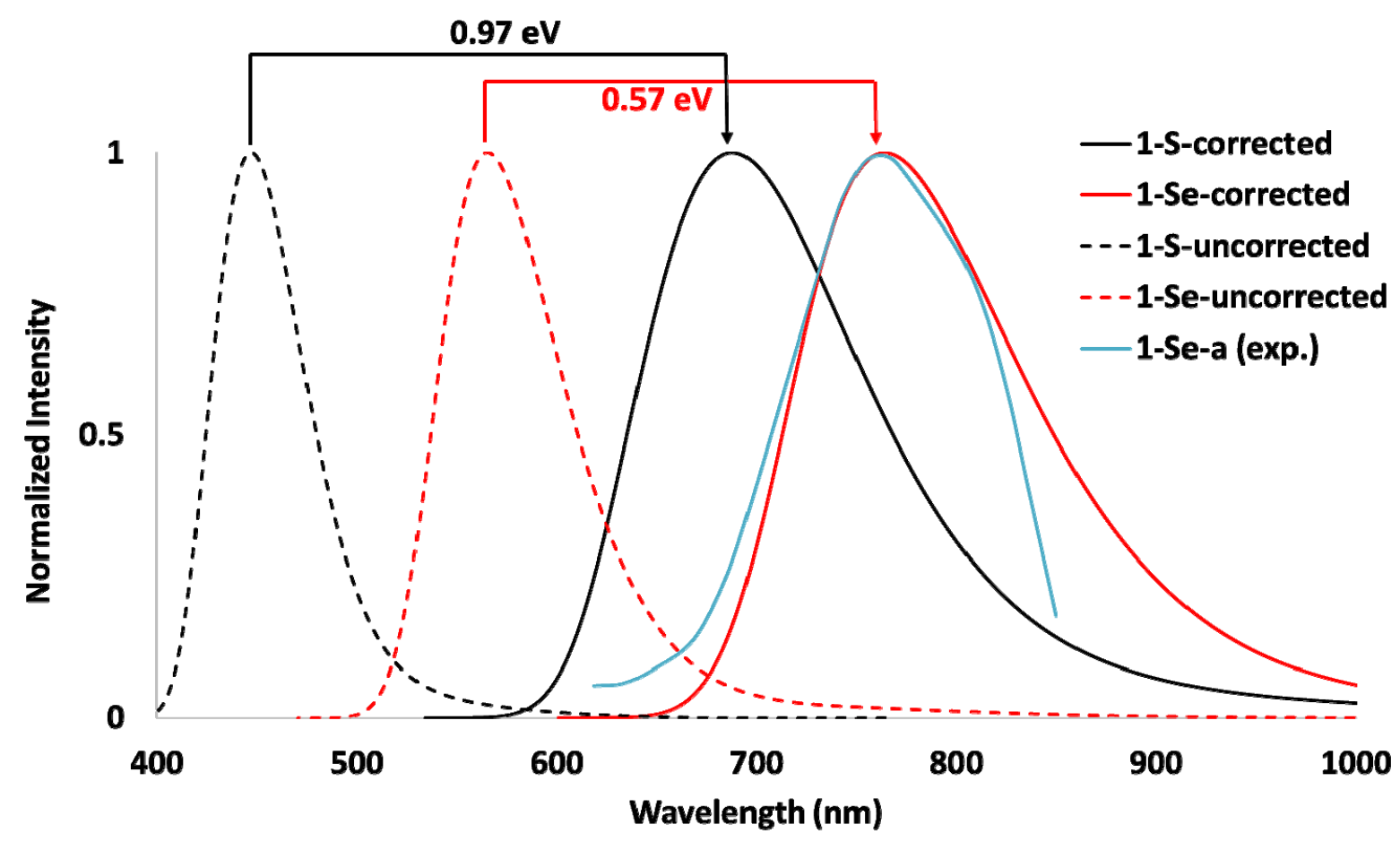

Figure 7. Simulated Phosphorescence Spectra of 1-S, 1-Se, and recorded spectrum of 1Se-a. Dashed lines correspond to the brut simulation. Plain lines correspond to the simulated spectra upon the energy corrections (shift $=0.97$ and $0.57 \mathrm{eV}$, for 1-S and 1Se, respectively, obtained by fitting the computed electronic and recorded phosphorescence wavelengths).

\section{Hypothetical related copper-encapsulated species}

Recently, some of us have reported the existence of 12 -vertex, namely $\left[\mathrm{Cu}_{12}\left(\mu_{12-}\right.\right.$ $\left.\mathrm{Cu})(\mathrm{CCR})_{4}\left(\mathrm{~S}_{2} \mathrm{CN}^{n} \mathrm{Bu}_{2}\right)_{6}\right]^{+}\left(\mathrm{R}=\mathrm{C}(\mathrm{O}) \mathrm{OMe}, \mathrm{C}_{6} \mathrm{H}_{4} \mathrm{~F}\right)$, having a $\mathrm{Cu}$-centered cuboctahedral core, which can be formally viewed as made of a $\mathrm{Cu}^{-}$anion encapsulated in a cage made of 12 $\mathrm{Cu}^{+}$vertices. ${ }^{61}$ Therefore, we have also investigated the possibility for our 12 -vertex cages to entrap a (formally) $\mathrm{Cu}^{-}$ion in the place of an iodide. The structural relationship of the resulting model, $\left[\mathrm{Cu}_{12}\left(\mu_{12}-\mathrm{Cu}\right)\left(\mu_{3}-\mathrm{I}\right)_{4}\left(\mathrm{E}_{2} \mathrm{PH}_{2}\right)_{6}\right]^{+}(\mathrm{E}=\mathrm{S}, \mathbf{6 - S}$; Se, 6-Se), with the above-reported 13-nuclear clusters is straightforward. Both compounds have ideal $T_{d}$ symmetry, with four triangular faces of the cuboctahedron capped by a $\mu_{3}$-ligand and the six octahedral faces capped by a $\left(\mu_{2}, \mu_{2}\right)$ dichacogenolate ligand. Both systems can be viewed as 2-electron species within the superatom model ${ }^{4,62}$ (jellium confirmation: $1 \mathrm{~S}^{2}$ $1 \mathrm{P}^{0.61,63-67}$ It turns out that in both cases ( $\mathrm{E}=\mathrm{S}$ and $\mathrm{Se}$ ) our hypothetical compounds were found to have small imaginary vibrational frequencies in their ideal $T_{d}$ symmetry (Table 5). An energy minimum (no imaginary frequencies) was found reducing 
symmetry to $C_{3}$, but the potential energy surface is very flat around these two stationary points. It is noteworthy that entrapping a formally $\mathrm{Cu}^{-}$into the cage results in a much larger contraction of the cage than in the case of $\mathrm{I}^{-}$(55\% vs. $25 \%$ in volume in the case of $\mathrm{E}=\mathrm{S}$ for instance). Consistently, $\Delta \mathrm{E}_{\text {Dist }}$ becomes important when the formally $\mathrm{Cu}^{-}$atom is entrapped into the dodecanuclear cluster cage. Unsurprisingly, the net charge of the entrapped $\mathrm{Cu}\left(\sim-0.5\right.$ in ideal $T_{d}$ symmetry) is fairly lower than that corresponding to its formal oxidation state $(-I)$, the two superatom electrons formally provided by the encapsulated $\mathrm{Cu}^{-}$being somehow shared with the 12 other metal centers.

According to the cage contraction, Wiberg indices and natural bond analysis, the dodecanuclear cluster cage needs more distortion to entrap $\mathrm{Cu}^{-}$than iodide. Therefore the possible existence of a $\mathrm{Cu}^{-}$encapsulated in the smaller penta-capped trigonal prism has been also investigated (see Tables 5 and 6 labeled 5-S and 5-Se). It turns out that, as for 1-Se, the energy minimum is not of $C_{3 h}$, but of lower $C_{3}$, symmetry. Moreover, it should be pointed out that when $\mathrm{Cu}^{-}$is entrapped instead of $\mathrm{I}^{-}$, the $C_{3 h} / C_{3}$ energy difference is larger $(0.11 \mathrm{eV}$ and $0.13 \mathrm{eV}$ for respectively 5-S and 5-Se). 
Table 5. Relevant metrical parameters computed for the $\left[\mathrm{Cu}_{11}\left(\mu_{9}-\mathrm{Cu}\right)\left(\mu_{3}-\right.\right.$ I $\left.)_{3}\left\{\mathrm{E}_{2} \mathrm{P}(\mathrm{OH})_{2}\right\}_{6}\right]^{+}$and $\left[\mathrm{Cu}_{12}\left(\mu_{12}-\mathrm{Cu}\right)\left(\mu_{3}-\mathrm{I}\right)_{4}\left\{\mathrm{E}_{2} \mathrm{PH}_{2}\right\}_{6}\right]^{+}(\mathrm{E}=\mathrm{S}, \mathrm{Se})$ models.

\begin{tabular}{|c|c|c|c|c|c|c|}
\hline Modeled cluster & Sym & $\begin{array}{l}\text { Imag. Freq. } \\
\left(\mathrm{cm}^{-1}\right)\end{array}$ & $\begin{array}{c}\Delta \mathrm{E} \\
(\mathrm{eV})\end{array}$ & $\begin{array}{c}\mathrm{Cu}-\mathrm{X} \\
(\AA \AA \AA \\
-\end{array}$ & $\begin{array}{l}\text { Cu-Icap } \\
(\AA ̊)\end{array}$ & $\begin{array}{c}\mathrm{Cu}-\mathrm{Cu} \\
(\AA)\end{array}$ \\
\hline \multirow{2}{*}{$\underset{\mathbf{( 5 - S )}}{\left[\mathrm{Cu}_{11}\left(\mu_{9}-\mathrm{Cu}\right)\left(\mu_{3}-\mathrm{I}\right)_{3}\left\{\mathrm{~S}_{2} \mathrm{P}(\mathrm{OH})_{2}\right\}_{6}\right]^{+}}$} & $C_{3 h}$ & $30 i, a^{\prime \prime}$ & 0.11 & $\begin{array}{l}6 \times 2.567 \\
3 \times 2.555\end{array}$ & $\begin{array}{l}6 \times 2.711 \\
3 \times 2.661\end{array}$ & $\begin{array}{l}6 \times 3.618 \\
3 \times 2.983 \\
6 \times 2.805 \\
6 \times 2.773 \\
6 \times 2.841\end{array}$ \\
\hline & $C_{3}$ & - & 0.00 & $\begin{array}{l}3 \times 2.624 \\
3 \times 2.570 \\
3 \times 2.594\end{array}$ & $\begin{array}{l}3 \times 2.629 \\
3 \times 2.939 \\
3 \times 2.641\end{array}$ & $\begin{array}{c}3 \times(4.097 ; 2.795) \\
3 \times 3.226 \\
3 \times(2.978 ; 2.970) \\
3 \times(2.659 ; 2.662) \\
3 \times(2.913 ; 2.750)\end{array}$ \\
\hline \multirow{2}{*}{$\begin{array}{c}{\left[\mathrm{Cu}_{11}\left(\mu_{9}-\mathrm{Cu}\right)\left(\mu_{3}-\mathrm{I}\right)_{3}\left\{\mathrm{Se}_{2} \mathrm{P}(\mathrm{OH})_{2}\right\}_{6}\right]^{+}} \\
\mathbf{( 5 - \mathrm { Se } )}\end{array}$} & $C_{3 h}$ & $38 i, a^{\prime \prime}$ & 0.14 & $\begin{array}{l}6 \times 2.550 \\
3 \times 2.554\end{array}$ & $\begin{array}{l}6 \times 2.729 \\
3 \times 2.660\end{array}$ & $\begin{array}{l}6 \times 3.519 \\
3 \times 3.080 \\
6 \times 2.806 \\
6 \times 2.792 \\
6 \times 2.798\end{array}$ \\
\hline & $C_{3}$ & - & 0.00 & $\begin{array}{l}3 \times 2.610 \\
3 \times 2.581 \\
3 \times 2.590\end{array}$ & $\begin{array}{l}3 \times 2.640 \\
3 \times 2.953 \\
3 \times 2.647\end{array}$ & $\begin{array}{c}3 \times(4.051 ; 2.768) \\
3 \times 3.270 \\
3 \times(2.997 ; 2.935) \\
3 \times(2.667 ; 2.699) \\
3 \times(2.849 ; 2.753)\end{array}$ \\
\hline \multirow[b]{2}{*}{$\begin{array}{c}{\left[\mathrm{Cu}_{12}\left(\mu_{12}-\mathrm{Cu}\right)\left(\mu_{3}-\mathrm{I}\right)_{4}\left\{\mathrm{~S}_{2} \mathrm{PH}_{2}\right\}_{6}\right]^{+}} \\
\mathbf{( 6 - S )}\end{array}$} & $T_{d}$ & $22 i, t_{1}$ & 0.00 & $12 \times 2.737$ & $12 \times 2.636$ & $\begin{array}{l}12 \times 2.700 \\
12 \times 2.774\end{array}$ \\
\hline & $C_{3}$ & - & 0.02 & $\begin{array}{l}3 \times 2.740 \\
3 \times 2.727 \\
3 \times 2.735 \\
3 \times 2.731\end{array}$ & $\begin{array}{l}3 \times 2.634 \\
3 \times 2.638 \\
3 \times 2.634 \\
3 \times 2.638\end{array}$ & $\begin{array}{l}3 \times(2.691 ; 2.713 ; 2.684 ; 2.700) \\
3 \times(2.757 ; 2.773 ; 2.775 ; 2.772)\end{array}$ \\
\hline \multirow[b]{2}{*}{$\begin{array}{c}{\left[\mathrm{Cu}_{12}\left(\mu_{12}-\mathrm{Cu}\right)\left(\mu_{3}-\mathrm{I}\right)_{4}\left\{\mathrm{Se}_{2} \mathrm{PH}_{2}\right\}_{6}\right]^{+}} \\
\mathbf{( 6 - S e )}\end{array}$} & $T_{d}$ & $\begin{array}{l}41 i, t_{1} \\
19 i, t_{2}\end{array}$ & 0.03 & $12 \times 2.731$ & $12 \times 2.634$ & $\begin{array}{l}12 \times 2.711 \\
12 \times 2.751\end{array}$ \\
\hline & $C_{3}$ & - & 0.00 & $\begin{array}{l}3 \times 2.700 \\
3 \times 2.728 \\
3 \times 2.737 \\
3 \times 2.732\end{array}$ & $\begin{array}{l}3 \times 2.630 \\
3 \times 2.631 \\
3 \times 2.638 \\
3 \times 2.638\end{array}$ & $\begin{array}{l}3 \times(2.725 ; 2.715 ; 2.745 ; 2.746) \\
3 \times(2.687 ; 2.691 ; 2.736 ; 2.750)\end{array}$ \\
\hline
\end{tabular}

Table 6. Relevant metrical parameters computed for the $\left[\mathrm{Cu}_{11}\left(\mu_{9}-\mathrm{Cu}\right)\left(\mu_{3}-\mathrm{I}\right)_{3}\left\{\mathrm{E}_{2} \mathrm{P}(\mathrm{OH})_{2}\right\}_{6}\right]^{+}$and $\left[\mathrm{Cu}_{12}\left(\mu_{12^{-}}\right.\right.$ $\left.\mathrm{Cu})\left(\mu_{3}-\mathrm{I}\right)_{4}\left\{\mathrm{E}_{2} \mathrm{PH}_{2}\right\}_{6}\right]^{+}(\mathrm{E}=\mathrm{S}, \mathrm{Se})$ models.

\begin{tabular}{|c|c|c|c|c|c|c|c|c|c|}
\hline Modeled clusters & Sym. & $\begin{array}{l}\text { HOMO- } \\
\text { LUMO gap } \\
\text { (eV) }\end{array}$ & $\begin{array}{l}\mathrm{BE} \\
(\mathrm{eV})\end{array}$ & $\begin{array}{c}\mathrm{DE} \\
(\mathrm{eV})\end{array}$ & $\begin{array}{l}\Delta \mathrm{E}_{\text {dist }} \\
(\mathrm{eV})\end{array}$ & $\begin{array}{l}\text { Sum of Cu-I } \mathrm{Cap} \\
\text { Wiberg indices }\end{array}$ & $\begin{array}{l}\text { Sum of } \mathrm{Cu}-\mathrm{Cu}_{\text {center }} \\
\text { Wiberg indices }\end{array}$ & $\begin{array}{l}\text { NAO net } \\
\text { charge } \\
\text { of } \\
\mathrm{Cu}_{\text {center }}\end{array}$ & $\begin{array}{l}\text { Population } \\
\text { of } \mathrm{Cu}_{\text {center }}\end{array}$ \\
\hline $5-S$ & $C_{3 h}$ & 3.18 & 11.96 & 10.11 & 1.85 & 0.63 & $\begin{array}{c}0.67 \\
3 \times 0.0691 \\
6 \times 0.0775 \\
0.68\end{array}$ & -0.53 & $\mathrm{~s}^{1.45} \mathrm{p}^{0.05} \mathrm{~d}^{9.99}$ \\
\hline 5-Se & $C_{3 h}$ & 2.90 & 12.03 & 10.03 & 2.00 & 0.59 & $\begin{array}{l}3 \times 0.0646 \\
6 \times 0.0802\end{array}$ & -0.51 & $\mathrm{~s}^{1.43} \mathrm{p}^{0.05} \mathrm{~d}^{9.99}$ \\
\hline $6-S$ & $T_{d}$ & 3.15 & 12.54 & 10.01 & 2.53 & 0.75 & $\begin{array}{c}0.66 \\
12 \times 0.0554\end{array}$ & -0.50 & $\mathrm{~s}^{1.44} \mathrm{p}^{0.04} \mathrm{~d}^{9.99}$ \\
\hline 6-Se & $T_{d}$ & 3.12 & 12.64 & 9.81 & 2.83 & 0.75 & $\begin{array}{c}0.68 \\
12 \times 0.0563\end{array}$ & -0.47 & $\mathrm{~S}^{1.41} \mathrm{p}^{0.05} \mathrm{~d}^{9.99}$ \\
\hline
\end{tabular}




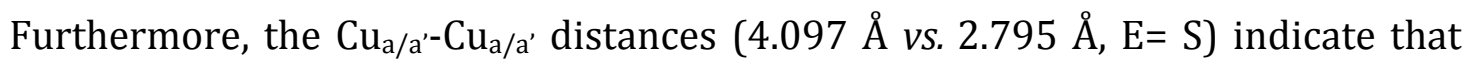
the trigonal prism architecture is strongly distorted. However, the $\mathrm{Cu}_{\mathrm{a} / \mathrm{b}}-\mathrm{Cu}_{\text {center }}$ bond lengths remain of the same order of magnitude when going from the ideal $C_{3 h}$ symmetry to the $C_{3}$ one. It should also be noticed that the nine $\mathrm{Cu}-\mathrm{Cu}^{-}$distances are nearly identical $(\sim 2.55 \AA)$. This result is at variance with the behavior of undecanuclear clusters containing an iodide at the center, in which there are six long $(\sim 3.2 \AA)$ and three short $(\sim 2.90 \AA ̊)$ distances (Table 5). The sum of Wiberg indices when $\mathrm{X}=\mathrm{Cu}^{-}$is also larger ( $c a$ $50 \%$ than when $X=I^{-}$. Furthermore, in opposition to the $X=I^{-}$cases, the Wiberg indices for $\mathrm{X}=\mathrm{Cu}^{-}$are in the same order of magnitude for the nine $\mathrm{Cu}-\mathrm{Cu}$ - interactions (Table 6). 


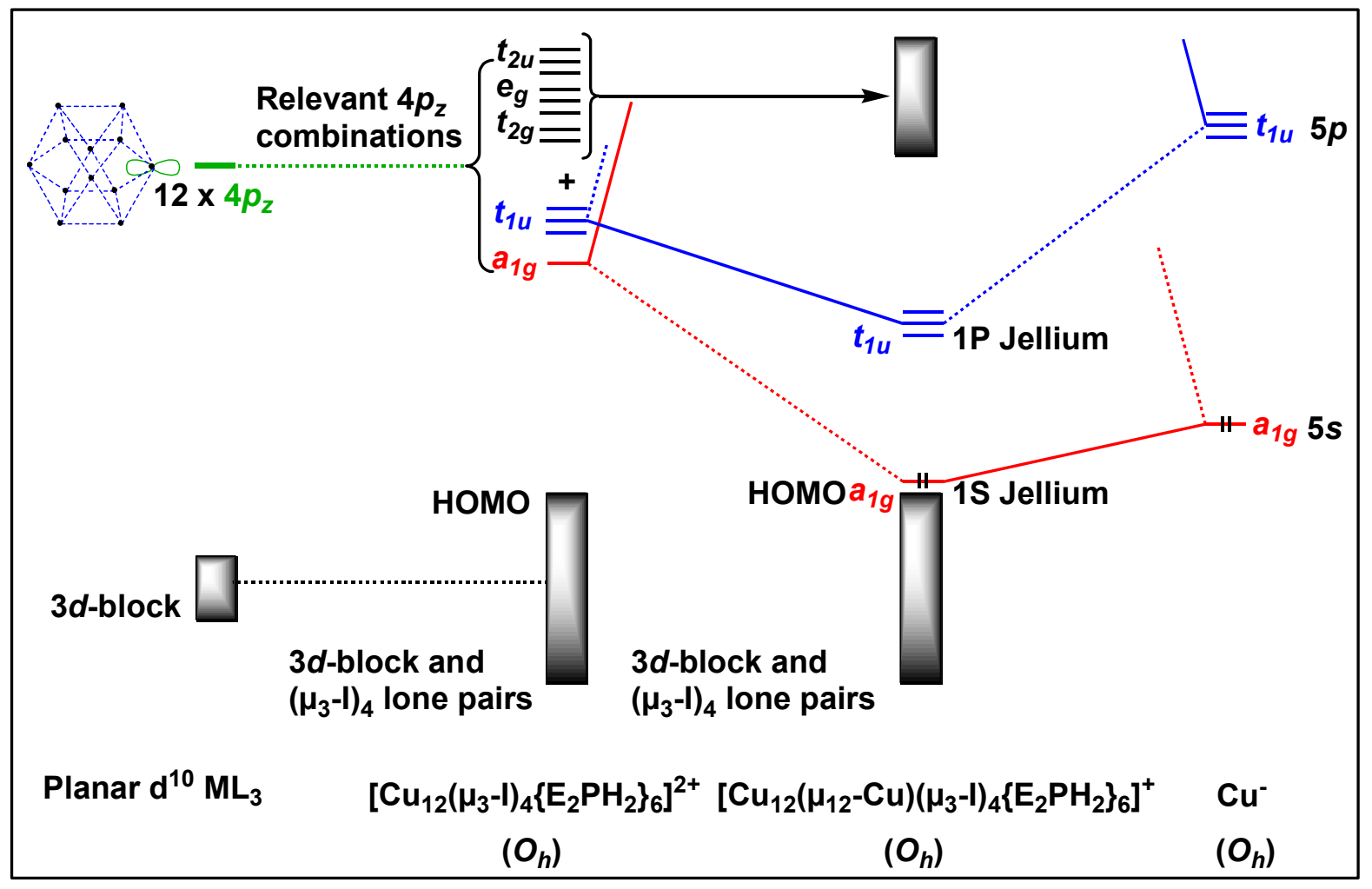

Figure 8. Qualitative MO diagram illustrating the interaction between the empty cage $\left[\mathrm{Cu}_{12}\left(\mu_{3}-\mathrm{I}\right)_{4}\left\{\mathrm{E}_{2} \mathrm{POR}_{2}\right\}_{6}\right]^{2+}(\mathrm{E}=\mathrm{S}, \mathrm{Se})$ and its $\mathrm{I}^{-}$host in the $\left[\mathrm{Cu}_{12}\left(\mu_{12}-\mathrm{Cu}\right)\left(\mu_{3}-\mathrm{I}\right)_{4}\left\{\mathrm{E}_{2} \mathrm{POR}_{2}\right\}_{6}\right]^{+}$ $(\mathrm{E}=\mathrm{S}, \mathrm{Se})$ cluster. The ideal $O_{h}$ pseudosymmetry of the $\mathrm{Cu}_{12}\left(\mu_{12}-\mathrm{Cu}\right)$ core is considered.

The optical behaviors of the hypothetical clusters were also investigated. Concerning the dodecanuclear clusters, TD-DFT calculations performed with the ideal symmetry constraint demonstrated that the highest absorption wavelengths fall around 530 and $560 \mathrm{~nm}$ for respectively the dithio and diseleno ligands. For the dithio ligand, this excitation can be mainly assigned to a HOMO to LUMO transition and corresponds to a charge transfer from the $1 \mathrm{~S}$ jellium orbital to the 1P ones (Figure 8 and 9) which can be characterized by a strong donation of the centered atom, the ligands and the metallic cage to the metallic cage. Indeed, the cluster core represents about $60 \%$ of the triply degenerate LUMO composition. For the diseleno ligands, the transition is more mixed but the trend is identical as for the dithio case, i.e. a charge transfer from the $1 \mathrm{~S}$ jellium to the $1 \mathrm{P}$ jellium one. 

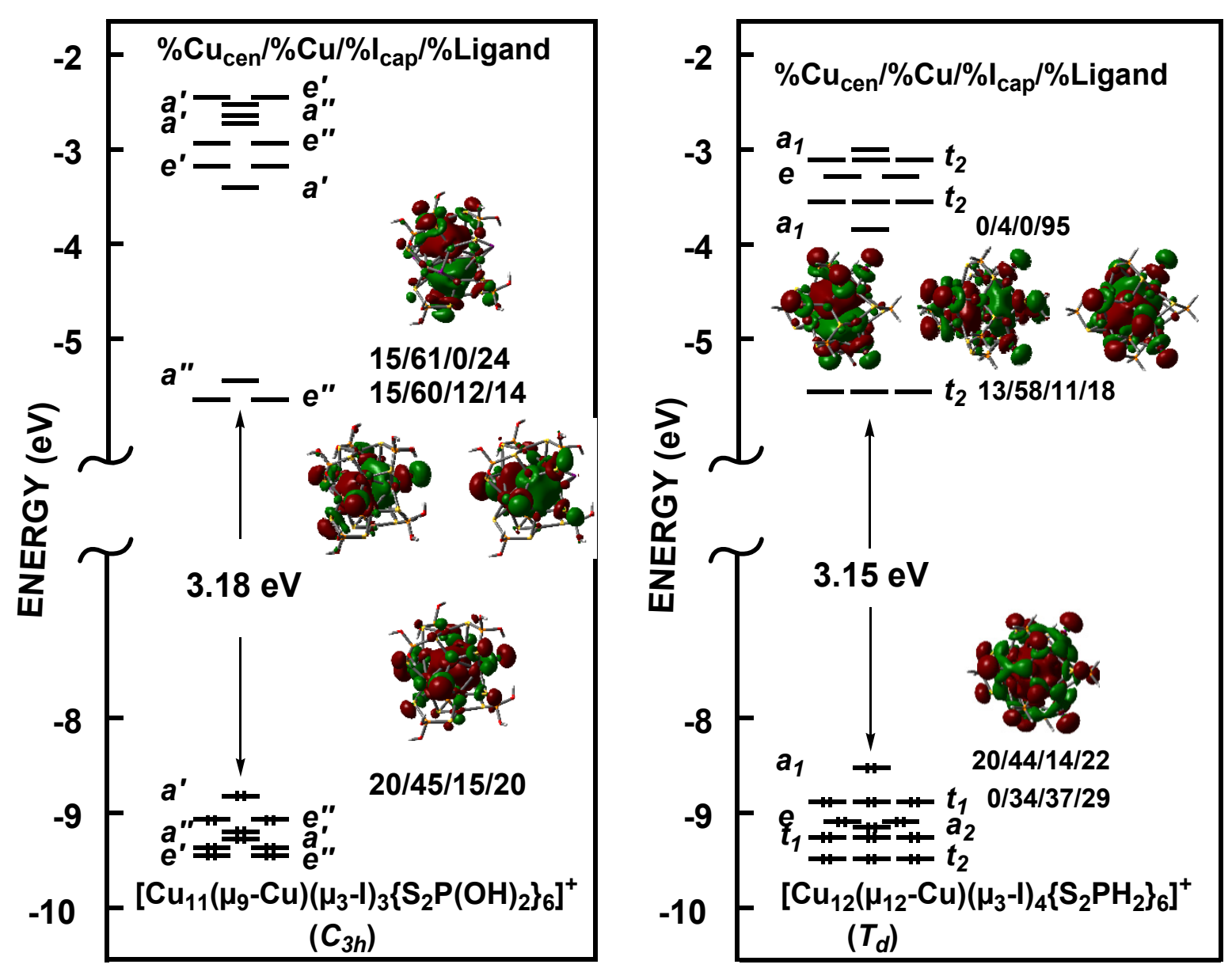

Figure 9. Kohn-Sham MO diagrams of $\left[\mathrm{Cu}_{11}\left(\mu_{9}-\mathrm{Cu}\right)\left(\mu_{3}-\mathrm{I}\right)_{3}\left\{\mathrm{~S}_{2} \mathrm{P}(\mathrm{OH})_{2}\right\}_{6}\right]^{+}$(left) and $\left[\mathrm{Cu}_{12}\left(\mu_{12}-\mathrm{Cu}\right)\left(\mu_{3}-\mathrm{I}\right)_{4}\left\{\mathrm{~S}_{2} \mathrm{PH}_{2}\right\}_{6}\right]^{+}$(right).

Concerning the hypothetical undenuclear cluster with, for instance, the dithioligands, two strong excitations have been computed enforcing the $C_{3 h}$ respectively at $511(e)$ and $493 \mathrm{~nm}\left(a^{\prime \prime}\right)$ (Figure 9). The highest excitation wavelength corresponds to a transition from the HOMO $\left(a^{\prime}\right)$ to the LUMO $\left(e^{\prime}\right)$. The second excitation occurs from HOMO to LUMO+2 ( $\left.a^{\prime \prime}\right)$. Both transitions correspond to a charge transfer from the metallic core and the centered $\mathrm{Cu}^{-}$to the metallic cage.

The luminescence properties of the hypothetical clusters have also been investigated. In general, these clusters are known to be phosphorescent therefore only this type of luminescence has been investigated. The computed electronic phosphorescence wavelengths were 763, 872, 698 and $686 \mathrm{~nm}$ for respectively 5-S, 5Se, 6-S and 6-Se. These values, close to the near-infrared region, suggest possible applications in devices such as sensors, OLED embedded systems, etc. 


\section{Conclusions}

This paper reports the main results of a combined experimental and theoretical analysis of large ligated copper(I) clusters encapsulating iodide or copper. DFT analysis of the model clusters 1-S, 1Se, 2-S and 2-Se indicates strong iono-covalent interaction between the encapsulated iodide and its copper(I) host cage. The cavity offered by these cages is particularly suited for encapsulating large anions such as iodide. Our computations point out a significant difference of volume between the empty and iodide-encapsulating cages. This result suggests that empty cages are likely not stable enough to be detected experimentally. Consistently, only undeca- and dodeca-nuclear clusters containing iodine have been isolated so far, in particular the two abovereported new clusters 1-Se-a and 1-Se-b. Their structure and optical properties are consistent with the computed results. Interestingly, their photoluminescent properties have been rationalized with the help of TD-DFT calculations including vibronic contributions to simulate the phosphorescence spectra. The possibility for such $\mathrm{Cu}(\mathrm{I})$ cages to encapsulate a formally $\mathrm{Cu}^{-}$anion $^{61}$ has also been investigated owing to its relatively similar size as I- Such hypothetical species are predicted to be stable 2electron superatomic species and TD-DFT calculations predict phosphorescence in the near-infrared region. ${ }^{68}$

\section{Supplementary Information}

Kohn-Sham orbital energy levels $\left[\mathrm{Cu}_{11}\left(\mu_{9}-\mathrm{I}\right)\left(\mu_{3}-\mathrm{I}\right)_{3}\left\{\mathrm{~S}_{2} \mathrm{P}(\mathrm{OH})_{2}\right\}_{6}\right]+$ and $\left[\mathrm{Cu}_{12}\left(\mu_{12}-\mathrm{I}\right)\left(\mu_{3}-\right.\right.$ I) $\left.{ }_{4}\left\{\mathrm{Se}_{2} \mathrm{PH}_{2}\right\}_{6}\right]^{+}$. Absorption, excitation, and emission data of compound 1-Se-a and 1-Seb. Optimized ground state structures of the computed clusters (mol2 file).

\section{Accession Codes}

CCDC 1546828 and 1546829 contain the supplementary crystallographic data for this paper. These data can be obtained free of charge via www.ccdc.cam.ac.uk/data request/cif, or by emailing data request@ccdc.cam.ac.uk, or by contacting the Cambridge Crystallographic Data Centre, 12 Union Road, Cambridge CB2 1EZ, UK; fax: +44 1223336033.

\section{Acknowledgement}

We thank Dr. Eric Faulques and Dr. Stéphane Jobic for fruitful discussions. Part of the calculations was run on the GENCI-CINES and GENCI-IDRISS French national 
computer centers which are acknowledged for their allowed resources (grant A0010807367). C. W. Liu acknowledges support from the Ministry of Science and Technology in Taiwan (MOST 106-2113-M-259-010).

\section{References}

(1) Li, G.; Jin, R. Atomically Precise Gold Nanoclusters as New Model Catalysts. Acc. Chem. Res. 2013, 46 (8), 1749-1758.

(2) Yamazoe, S.; Koyasu, K.; Tsukuda, T. Nonscalable Oxidation Catalysis of Gold Clusters. Acc. Chem. Res. 2014, 47 (3), 816-824.

(3) Schmid, G. The Relevance of Shape and Size of Au ${ }_{55}$ Clusters. Chem. Soc. Rev. 2008, 37 (9), 1909-1930.

(4) Hakkinen, H. Atomic and Electronic Structure of Gold Clusters: Understanding Flakes, Cages and Superatoms from Simple Concepts. Chem. Soc. Rev. 2008, 37 (9), 1847-1859.

(5) Daniel, M.-C.; Astruc, D. Gold Nanoparticles: Assembly, Supramolecular Chemistry, Quantum-Size-Related Properties, and Applications toward Biology, Catalysis, and Nanotechnology. Chem. Rev. 2004, 104 (1), 293-346.

(6) Parker, J. F.; Fields-Zinna, C. A.; Murray, R. W. The Story of a Monodisperse Gold Nanoparticle: $\mathrm{Au}_{25} \mathrm{~L}_{18}$. Acc. Chem. Res. 2010, 43 (9), 1289-1296.

(7) Latouche, C.; Liu, C. W.; Saillard, J.-Y. Encapsulating Hydrides and Main-Group Anions in $\mathrm{d}^{10}$-Metal Clusters Stabilized by 1,1-Dichalcogeno Ligands. J. Clust. Sci. 2014, 25 (1), 147-171.

(8) Dhayal, R. S.; van Zyl, W. E.; Liu, C. W. Polyhydrido Copper Clusters: Synthetic Advances, Structural Diversity, and Nanocluster-to-Nanoparticle Conversion. Acc. Chem. Res. 2016, 49 (1), 86-95.

(9) Dhayal, R. S.; Liao, J.-H.; Lin, Y.-R.; Liao, P.-K.; Kahlal, S.; Saillard, J.-Y.; Liu, C. W. A Nanospheric Polyhydrido Copper Cluster of Elongated Triangular Orthobicupola Array: Liberation of H2 from Solar Energy. J. Am. Chem. Soc. 2013, 135 (12), 47044707.

(10) Liu, C. W.; Sarkar, B.; Huang, Y.-J.; Liao, P.-K.; Wang, J.-C.; Saillard, J.-Y.; Kahlal, S. Octanuclear Copper(I) Clusters Inscribed in a $\mathrm{Se}_{12}$ Icosahedron: Anion-Induced Modulation of the Core Size and Symmetry. J. Am. Chem. Soc. 2009, 131 (31), 11222-11233.

(11) Liu, C. W.; Chang, H.-W.; Sarkar, B.; Saillard, J.-Y.; Kahlal, S.; Wu, Y.-Y. Stable Silver(I) Hydride Complexes Supported by Diselenophosphate Ligands. Inorg. Chem. 2010, 49 (2), 468-475.

(12) Latouche, C.; Kahlal, S.; Furet, E.; Liao, P.-K.; Lin, Y.-R.; Fang, C.-S.; Cuny, J.; Liu, C. W.; Saillard, J.-Y. Shape Modulation of Octanuclear Cu(I) or Ag(I) Dichalcogeno Template Clusters with Respect to the Nature of Their Encapsulated Anions: A Combined Theoretical and Experimental Investigation. Inorg. Chem. 2013, 52 (13), 7752-7765.

(13) Latouche, C.; Kahlal, S.; Lin, Y.-R.; Liao, J.-H.; Furet, E.; Liu, C. W.; Saillard, J.-Y. Anion Encapsulation and Geometric Changes in Hepta-and Hexanuclear Copper(I) Dichalcogeno Clusters: A Theoretical and Experimental Investigation. Inorg. Chem. 2013, 52 (22), 13253-13262.

(14) Liu, C. W.; Chen, H.-C.; Liu, C. W.; Wang, J.-C.; Keng, T.-C. First Selenide-Centered 
$\mathrm{Cu}_{8}{ }_{8}$ Cubic Clusters Containing Dialkyl Diselenophosphate Ligands. X-Ray Structure of $\left\{\mathrm{Cu}_{8}\left(\mu_{8}-\mathrm{Se}\right)\left[\mathrm{Se}_{2} \mathrm{P}\left(\mathrm{OPr}^{\mathrm{i}}\right)_{2}\right]_{6}\right\}$. Chem. Commun. 1998, No. 17, 1831-1832.

(15) Fenske, D.; Rothenberger, A.; Shafaei Fallah, M. Synthesen Und Kristallstrukturen von $\mathrm{Cu}$ - Und Ag-Komplexen Mit Dithiophosphinat- Und TrithiophosphonatLiganden. Zeitschrift für Anorg. und Allg. Chemie 2004, 630 (6), 943-947.

(16) Liu, C. W.; Stubbs, T.; Staples, R. J.; Fackler, J. P. Syntheses and Structural Characterizations of Two New Cu-S Clusters of Dialkyl Dithiophosphates: A Sulfide-Centered $\mathrm{Cu}_{8}{ }_{8} \mathrm{Cube},\left\{\mathrm{Cu}_{8}\left[\mathrm{~S}_{2} \mathrm{P}\left(\mathrm{O}^{\mathrm{i}} \mathrm{Pr}\right)_{2}\right]_{6}\left(\mu_{8}-\mathrm{S}\right)\right\}$, and a Distorted Octahedral $\left\{\mathrm{Cu}_{6}\left[\mathrm{~S}_{2} \mathrm{P}(\mathrm{OEt})_{2}\right]_{6} \cdot 2 \mathrm{H}_{2} \mathrm{O}\right\}$ Cluster. J. Am. Chem. Soc. 1995, 117 (38), 9778-9779.

(17) Huang, Z.; Lu, S.; Huang, J.; Wu, D.; Huang, J. Synthesis and Structure of $\mathrm{Cu}_{8} \mathrm{~S}\left[\mathrm{~S}_{2} \mathrm{P}\left(\mathrm{OC}_{2} \mathrm{H}_{5}\right)_{2}\right]_{6}$. Jiegou Huaxue (J. Struct. Chem) 1991, 10, 213.

(18) Wu, D.; Huang, J.; Lin, Y.; Huang, J. Study on the Reaction Performance of Cluster Compound - a Reaction of copper(+2) Capturing Ligands from Molybdenum Cluster and the Crystal Structure of Its Product $\mathrm{Cu}_{8} \mathrm{Cl}_{2}\left[\mathrm{~S}_{2} \mathrm{P}(\mathrm{OEt})_{2}\right]_{6}$. Sci. Sin. Ser. B Chem. Biol. (English Ed.) 1988, 31 (7), 800.

(19) Birker, P. J. M. W. L.; Freeman, H. C. Structure, Properties, and Function of a copper(I)-copper(II) Complex of D-Penicillamine: pentathallium(I) $\mu 8$-Chlorododeca(D-penicillaminato)octacuprate(I)hexacuprate(II) N-Hydrate. J. Am. Chem. Soc. 1977, 99 (21), 6890-6899.

(20) Birker, P. J. M. W. L. Copper Thiolate Cluster Compounds. X-Ray Structure and Properties of $\quad$ pentathallium(I) $\quad \mu 8$-Chloro-Dodecakis $(\alpha-$ mercaptoisobutyrato)octacuprate(I)hexacuprate(II) Hydrate, $\mathrm{Tl}_{5}\left[\mathrm{Cu}_{6}{ }_{6} \mathrm{Cu}_{8}{ }_{8}\left(\mathrm{SC}\left(\mathrm{CH}_{3}\right)_{2} \mathrm{COO}\right)_{12} \mathrm{Cl}\right] \sim 12 \mathrm{H}_{2} \mathrm{O}$. Inorg. Chem. 1979, 18 (12), 3502-3506.

(21) Schugar, H. J.; Ou, C.-C.; Thich, J. A.; Potenza, J. A.; Felthouse, T. R.; Haddad, M. S.; Hendrickson, D. N.; Furey, W.; Lalancette, R. A. Crystal Structure and Magnetic Properties of the Cluster Complex $\mathrm{Cu}_{8} \mathrm{Cu}_{6} \mathrm{II}_{6}\left[\mathrm{SC}\left(\mathrm{CH}_{3}\right)_{2} \mathrm{CH}_{2} \mathrm{NH}_{2}\right]_{12} \mathrm{Cl}_{\cdot 3.5} \mathrm{SO}_{4} \sim 20 \mathrm{H} 2 \mathrm{O}$, a Mixed-Valence Copper-Mercaptide Species. Inorg. Chem. 1980, 19 (2), 543-552.

(22) Liao, J.-H.; Chang, H.-W.; You, H.-C.; Fang, C.-S.; Liu, C. W. Tetrahedral-Shaped Anions as a Template in the Synthesis of High-Nuclearity Silver(I) Dithiophosphate Clusters. Inorg. Chem. 2011, 50 (6), 2070-2072.

(23) Haiduc, I. Inverse Coordination - An Emerging New Chemical Concept. Oxygen and Other Chalcogens as Coordination Centers. Coord. Chem. Rev. 2017, 338, 1-26.

(24) Edwards, A. J.; Dhayal, R. S.; Liao, P.-K.; Liao, J.-H.; Chiang, M.-H.; Piltz, R. O.; Kahlal, S.; Saillard, J.-Y.; Liu, C. W. Chinese Puzzle Molecule: A 15 Hydride, 28 Copper Atom Nanoball. Angew. Chemie Int. Ed. 2014, 53 (28), 7214-7218.

(25) Li, Y.-J.; Latouche, C.; Kahlal, S.; Liao, J.-H.; Dhayal, R. S.; Saillard, J.-Y.; Liu, C. W. A $\mu$ 9-Iodide in a Tricapped Trigonal-Prismatic Geometry. Inorg. Chem. 2012, 51 (14), 7439-7441.

(26) Liao, J.-H.; Latouche, C.; Li, B.; Kahlal, S.; Saillard, J.-Y.; Liu, C. W. A TwelveCoordinated Iodide in a Cuboctahedral silver(I) Skeleton. Inorg. Chem. 2014, 53 (4), 2260-2267.

(27) Wei, Z.-H.; Ni, C.-Y.; Li, H.-X.; Ren, Z.-G.; Sun, Z.-R.; Lang, J.-P. [PyH][\{TpMo( $\mu 3-$ S) $\left.\left.{ }_{4} \mathrm{Cu}_{3}\right\}_{4}\left(\mu_{12}-\mathrm{I}\right)\right]$ : A Unique Tetracubane Cluster Derived from the $\mathrm{S}-\mathrm{S}$ Bond Cleavage and the Iodide Template Effects and Its Enhanced NLO Performances. Chem. Commun. 2013, 49 (42), 4836.

(28) Frisch, M. J.; Trucks, G. W.; Schlegel, H. B.; Scuseria, G. E.; Robb, M. A.; Cheeseman, J. R.; Scalmani, G.; Barone, V.; Mennucci, B.; Petersson, G. A.; et al. Gaussian09 GDV. 2015. 
(29) Ernzerhof, M.; Scuseria, G. E. Assessment of the Perdew-Burke-Ernzerhof Exchange-Correlation Functional. J. Chem. Phys. 1999, 110 (11), 5029-5036.

(30) Adamo, C.; Barone, V. Toward Reliable Density Functional Methods without Adjustable Parameters: The PBE0 Model. J. Chem. Phys. 1999, 110 (13), 61586170.

(31) Weigend, F.; Ahlrichs, R. Balanced Basis Sets of Split Valence Triple Zeta Valence and Quadruple Zeta Valence Quality for $\mathrm{H}$ to Rn: Design and Assessment of Accuracy. Phys. Chem. Chem. Phys. 2005, 7 (18), 3297-3305.

(32) Dhayal, R. S.; Lin, Y.-R.; Liao, J.-H.; Chen, Y.-J.; Liu, Y.-C.; Chiang, M.-H.; Kahlal, S.; Saillard, J.-Y.; Liu, C. W. $\left[\mathrm{Ag}_{20}\left\{\mathrm{~S}_{2} \mathrm{P}(\mathrm{OR})_{2}\right\}_{12}\right]$ : A Superatom Complex with a Chiral Metallic Core and High Potential for Isomerism. Chem. - A Eur. J. 2016, 22 (29), 9943-9947.

(33) Dhayal, R. S.; Liao, J.-H.; Wang, X.; Liu, Y.-C.; Chiang, M.; Kahlal, S.; Saillard, J.; Liu, C. W. Diselenophosphate-Induced Conversion of an Achiral $\left[\mathrm{Cu}_{20} \mathrm{H}_{11}\left\{\mathrm{~S}_{2} \mathrm{P}\left(\mathrm{O}^{\mathrm{i}} \mathrm{Pr}\right)_{2}\right\}_{9}\right]$ into a Chiral $\left[\mathrm{Cu}_{20} \mathrm{H}_{11}\left\{\mathrm{Se}_{2} \mathrm{P}\left(\mathrm{O}^{\mathrm{i}} \mathrm{Pr}\right)_{2}\right\}_{9}\right]$ Polyhydrido Nanocluster. Angew. Chemie 2015, 127 (46), 13808-13812.

(34) Chang, H.-W.; Shiu, R.-Y.; Fang, C.-S.; Liao, J.-H.; Kishore, P. V. V. N.; Kahlal, S.; Saillard, J.-Y.; Liu, C. W. A Sulfide (Selenide)-Centered Nonanuclear Silver Cluster: A Distorted and Flexible Tricapped Trigonal Prismatic Ag9 Framework. J. Clust. Sci. 2017, 28 (2), 679-694.

(35) Liu, C. W.; Lin, Y. R.; Fang, C. S.; Latouche, C.; Kahlal, S.; Saillard, J. Y. (E = Se, S): Precursors for the Fabrication of Silver Nanoparticles. Inorg. Chem. 2013, 52 (4), 2070-2077.

(36) Latouche, C.; Skouteris, D.; Palazzetti, F.; Barone, V. TD-DFT Benchmark on Inorganic Pt(II) and Ir(III) Complexes. J. Chem. Theory Comput. 2015, 11 (7), 3281-3289.

(37) Glendening, E. D.; Badenhoop, J. K.; Reed, A. E.; Carpenter, J. E.; Bohmann, J. A.; Morales, C. M.; Weinhold, F. Nbo 5. Nbo 5.02001.

(38) Barone, V.; Bloino, J.; Biczysko, M.; Santoro, F. Fully Integrated Approach to Compute Vibrationally Resolved Optical Spectra: From Small Molecules to Macrosystems. J. Chem. Theory Comput. 2009, 5 (3), 540-554.

(39) Barone, V.; Baiardi, A.; Biczysko, M.; Bloino, J.; Cappelli, C.; Lipparini, F. Implementation and Validation of a Multi-Purpose Virtual Spectrometer for Large Systems in Complex Environments. Phys. Chem. Chem. Phys. 2012, 14 (36), 1240412422.

(40) Massuyeau, F.; Faulques, E.; Latouche, C.; Barone, V. New Insights into the Vibrational and Optical Signatures of Trans-Stilbene via Integrated Experimental and Quantum Mechanical Approaches. Phys. Chem. Chem. Phys. 2016, 18 (28), 19378-19385.

(41) Belaidi, H.; Belaidi, S.; Katan, C.; Latouche, C.; Boucekkine, A. Vibronic Coupling to Simulate the Phosphorescence Spectra of Ir(III)-Based OLED Systems: TD-DFT Results Meet Experimental Data. J. Mol. Model. 2016, 22 (11), 265.

(42) Vazart, F.; Latouche, C. Validation of a Computational Protocol to Simulate near IR Phosphorescence Spectra for Ru(II) and Ir(III) Metal Complexes. Theor. Chem. Acc. 2015, 134 (12), 1-7.

(43) Latouche, C.; Baiardi, A.; Barone, V. Virtual Eyes Designed for Quantitative Spectroscopy of Inorganic Complexes: Vibronic Signatures in the Phosphorescence Spectra of Terpyridine Derivatives. J. Phys. Chem. B 2015, 119 
(24), 7253-7257.

(44) Vazart, F.; Latouche, C.; Bloino, J.; Barone, V. Vibronic Coupling Investigation to Compute Phosphorescence Spectra of Pt(II) Complexes. Inorg. Chem. 2015, 54 (11), 5588-5595.

(45) Licari, D.; Baiardi, A.; Biczysko, M.; Egidi, F.; Latouche, C.; Barone, V. Implementation of a Graphical User Interface for the Virtual Multifrequency Spectrometer: The VMS-Draw Tool. J. Comput. Chem. 2015, 36 (5), 321-334.

(46) Gorelsky, S. I. AOMix: Program for Molecular Orbital Analysis; 2009.

(47) Momma, K.; Izumi, F. VESTA: A Three-Dimensional Visualization System for Electronic and Structural Analysis. J. Appl. Crystallogr. 2008, 41 (3), 653-658.

(48) Momma, K.; Izumi, F. VESTA 3 for Three-Dimensional Visualization of Crystal, Volumetric and Morphology Data. J. Appl. Crystallogr. 2011, 44 (6), 1272-1276.

(49) Bruker Analytical X-ray System: Madison, (WI, 1995). SAINT V4.043: Software for the CCD Detector System;

(50) Sheldrick, G. M. SADABS. (University of Göttingen), Göttingen 1996.

(51) Bruker Analytical X-ray System: SHELXL Program Library for Structure Solution and Molecular Graphics. Madison, Wisconsin, USA 2001.

(52) Liu, C. W.; Shang, I.-J.; Fu, R.-J.; Liaw, B.-J.; Wang, J.-C.; Chang, I.-J. SeleniumCentered, Undecanuclear Silver Cages Surrounded by Iodo and Dialkyldiselenophosphato Ligands. Syntheses, Structures, and Photophysical Properties. Inorg. Chem. 2006, 45 (5), 2335-2340.

(53) Liu, C. W.; Feng, C.-S.; Fu, R.-J.; Chang, H.-W.; Saillard, J.-Y.; Kahlal, S.; Wang, J.-C.; Chang, I.-J. Structure, Photophysical Properties, and DFT Calculations of SelenideCentered Pentacapped Trigonal Prismatic Silver(I) Clusters. Inorg. Chem. 2010, 49 (11), 4934-4941.

(54) Liu, C. W.; Hung, C.-M.; Santra, B. K.; Chu, Y.-H.; Wang, J.-C.; Lin, Z. A Nonacoordinated Bridging Selenide in a Tricapped Trigonal Prismatic Geometry Identified in Undecanuclear Copper Clusters: Syntheses, Structures, and DFT Calculations. Inorg. Chem. 2004, 43 (14), 4306-4314.

(55) Li, B.; Liao, J.-H.; Tang, H.-T.; Li, Y.-J.; Liu, C. W. Substitution Reactions on a Hypercoordinated Main-Group Element Encapsulated in a Pentacapped Trigonal Prismatic Copper Cage. Dalton Trans. 2013, 42 (40), 14384.

(56) Liu, C.-W.; Hung, C.-M.; Wang, J.-C.; Keng, T.-C. Characterization of $\mathrm{Cu}_{11}(\mu 9-\mathrm{Se})([\mu 3-$ $\mathrm{I}_{3}\left[\mathrm{Se}_{2} \mathrm{P}(\mathrm{OR})_{2}\right]_{6}(\mathrm{R}=\mathrm{Pr}, \mathrm{Pr} \mathrm{i})$ by X-Ray Diffraction and Multinuclear NMR J. Chem. Soc., Dalton Trans. 2002, No. 18, 3482-3488.

(57) Baiardi, A.; Bloino, J.; Barone, V. Accurate Simulation of Resonance-Raman Spectra of Flexible Molecules: An Internal Coordinates Approach. J. Chem. Theory Comput. 2015, 11 (7), 3267-3280.

(58) Bloino, J.; Biczysko, M.; Santoro, F.; Barone, V. General Approach to Compute Vibrationally Resolved One-Photon Electronic Spectra. J. Chem. Theory Comput. 2010, 6 (4), 1256-1274.

(59) Banerjee, S.; Baiardi, A.; Bloino, J.; Barone, V. Vibronic Effects on Rates of Excitation Energy Transfer and Their Temperature Dependence. J. Chem. Theory Comput. 2016, 12 (5), 2357-2365.

(60) Baiardi, A.; Latouche, C.; Bloino, J.; Barone, V. Accurate yet Feasible Computations of Resonance Raman Spectra for Metal Complexes in Solution: [Ru(bpy) $]^{(2+)}$ as a Case Study. Dalton Trans. 2014, 43 (47), 17610-17614.

(61) Chakrahari, K. K.; Liao, J.-H.; Kahlal, S.; Liu, Y.-C.; Chiang, M.-H.; Saillard, J.-Y.; Liu, C. 
W. $\left.\left[\mathrm{Cu}_{13}\left\{\mathrm{~S}_{2} \mathrm{CNNBu}_{2}\right\}_{6} \text { (Acetylide) }\right]_{4}\right]^{+}:$A Two-Electron Superatom. Angew. Chemie Int. Ed. 2016, 55 (47), 14704-14708.

(62) Walter, M.; Akola, J.; Lopez-Acevedo, O.; Jadzinsky, P. D.; Calero, G.; Ackerson, C. J.; Whetten, R. L.; Gronbeck, H.; Hakkinen, H. A Unified View of Ligand-Protected Gold Clusters as Superatom Complexes. Proc. Natl. Acad. Sci. 2008, 105 (27), 91579162.

(63) Gam, F.; Paez-Hernandez, D.; Arratia-Perez, R.; Liu, C. W.; Kahlal, S.; Saillard, J.-Y.; Muñoz-Castro, A. Coinage Metal Superatomic Cores: Insights into Their Intrinsic Stability and Optical Properties from Relativistic DFT Calculations. Chem. - A Eur. J. 2017, 23 (47), 11330-11337.

(64) Kahlal, S.; Liu, C. W.; Saillard, J.-Y. Ag13-Centered Cuboctahedral Architecture in Inorganic Cluster Chemistry: A DFT Investigation. Inorg. Chem. 2017, 56 (3), 1209-1215.

(65) Albano, V. G.; Grossi, L.; Longoni, G.; Monari, M.; Mulley, S.; Sironi, A. Synthesis and Characterization of the Paramagnetic $\left[\mathrm{Ag}_{13} \mathrm{Fe}_{8}(\mathrm{CO})_{32}\right]^{4-}$ Tetraanion: A Cuboctahedral Ag13 Cluster Stabilized by Fe(CO) 4 Groups Behaving as 4-Electron Donors. J. Am. Chem. Soc. 1992, 114 (14), 5708-5713.

(66) Albano, V. G.; Calderoni, F.; Iapalucci, M. C.; Longoni, G.; Monari, M.; Zanello, P. Synthesis, chemical, and electrochemical characterization of the $\left[\operatorname{Ag}_{13}\left\{\mu_{3}-\right.\right.$ $\left.\left.\mathrm{Fe}(\mathrm{CO})_{4}\right\}\right]^{n-}(n=3,4,5)$ cluster anions: X-Ray structural determination of $\left[\mathrm{N}\left(\mathrm{PPh}_{3}\right)_{2}\right]_{3}\left[\mathrm{Ag}_{12}\left(\mu_{12}-\mathrm{Ag}\right)\left\{\mu_{3} \mathrm{Fe}(\mathrm{CO})_{4}\right\}_{8}\right]$ J. Clust. Sci. 1995, 6 (1), 107-123.

(67) Nguyen, T.-A. D.; Jones, Z. R.; Goldsmith, B. R.; Buratto, W. R.; Wu, G.; Scott, S. L.; Hayton, T. W. A $\mathrm{Cu}_{25}$ Nanocluster with Partial $\mathrm{Cu}(0)$ Character. J. Am. Chem. Soc. 2015, 137 (41), 13319-13324.

(68) Exploratory calculations suggested by a reviewer indicate that encapsulation of a formally $\mathrm{Zn}(0)$ atom should be also possible. 


\section{For Table of content only}

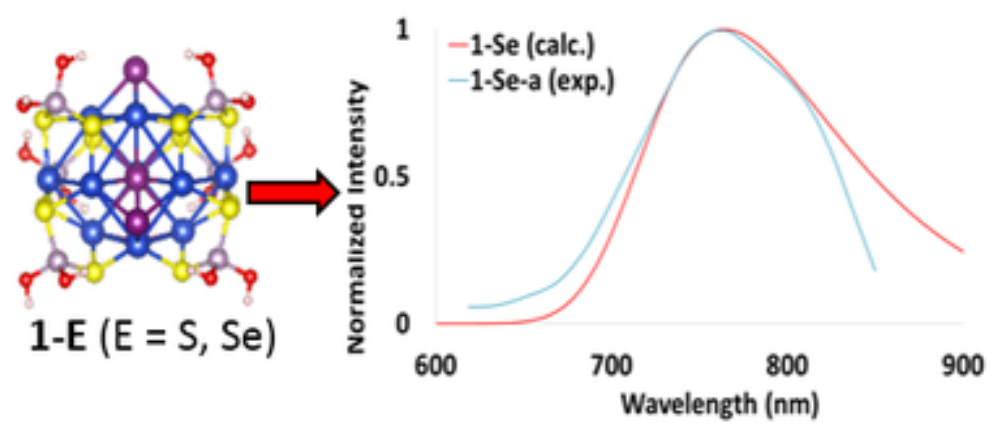

Synopsis. A combined computational/experimental investigation has been carried out on undeca- and dodeca-nuclear $\mathrm{Cu}(\mathrm{I})$ cages encapsulating iodide. These compounds exhibit interesting photoluminescent properties, which have been fully investigated by TD-DFT calculations using the vibronic approach to simulate the phosphorescent spectra. Calculations indicate that replacing formally the encapsulated iodide by a $\mathrm{Cu}^{-}$ anion should also lead to stable species which can be described as 2-electron superatoms with near-IR photoluminecent behavior. 